(C) Dereito Vol.28, n01:9-44 (Xaneiro-Xuño, 2019) • ISSN 1132-9947

\title{
CUESTIONES TÉCNICAS (Y SIMBÓLICAS) DE LA VECINDAD CIVIL A LA LUZ DE LA PROPOSICIÓN DE LEY PRESENTADA POR LAS CORTES DE ARAGÓN
}

Technical (and symbolic) issues regarding the regional citizenship in light of the Legislative Proposal submitted by the Parliament of Aragón

DOI: http://dx.doi.org/10.15304/dereito.28.1.5849

\author{
JULia AmmeRman YeBra ${ }^{1}$ \\ Investigadora Predoctoral de Derecho Civil \\ Universidade de Santiago de Compostela \\ julia.ammerman@usc.es
}

\section{Resumen}

as Cortes de Aragón presentaron en septiembre de 2016 una Proposición de Ley por la que se modificaba el Código civil en relación con el estatuto personal y vecindad civil. Esencialmente pretendían variar tres aspectos del régimen de atribución y adquisición de la vecindad civil, siendo el más destacado de ellos la supresión de su adquisición automática por residencia continuada en otro territorio durante diez años. Las comparecencias de los expertos y el debate parlamentario generado con la Proposición de Ley pusieron sobre la mesa no solo aspectos de técnica legislativa, sino también cuestiones «simbólicas» de la vecindad civil.

Palabras clave: Derecho interregional; Plurilegislación civil española; Vecindad civil; Voluntad expresa; Identidad.

\section{Abstract}

In September 2016, the Parliament of Aragon presented a Legislative Proposal modifying the Spanish Civil Code in regard to personal status and regional citizenship. Basically, they sought to change three aspects of the attribution and acquisition of regional citizenship, the most significant being the one which suppresses the automatic acquisition of said citizenship when residing continuously in another territory for ten years. The hearings of the experts and the parliamentary debate generated by the Legislative Proposal put forward not only technical aspects, but also «symbolic» issues concerning regional citizenship.

Keywords: Interregional law; Situation of more than one civil legal system in Spain; Regional citizenship; Expressed will; Identity.

\section{SUMARIO}

1.- INTRODUCCIÓN. 2.- UNA CUESTIÓN PREVIA: LA COMPETENCIA EXCLUSIVA DEL ESTADO SOBRE EL RÉGIMEN JURÍDICO DE LA VECINDAD CIVIL. 3.- BREVES NOTAS SOBRE LA ATRIBUCIÓN, ADQUISICIÓN, CONSERVACIÓN, RECUPERACIÓN Y PÉRDIDA DE LA VECINDAD CIVIL.

${ }^{1}$ http://orcid.org/0000-0001-7858-0541

Recibido: 28/01/2019. Aceptado: 15/05/2019. 
3.1.- Atribución por filiación y nacimiento. 3.2.- Elección por los progenitores o por el propio interesado. 3.3.- Adquisición por residencia. 3.4.- Conservación de la vecindad civil. 3.5. Recuperación de la vecindad civil perdida. 4.- LA PROPOSICIÓN DE LEY POR LA QUE SE MODIFICA EL CÓDIGO CIVIL EN RELACIÓN CON EL ESTATUTO PERSONAL Y LA VECINDAD CIVIL. 4.1.- Ampliación de la facultad de opción del hijo. 4.2.Supresión de la adquisición por residencia continuada de diez años. 4.3.Recuperación de la vecindad civil perdida. 5.- DOS CUESTIONES TANGENCIALES A LA PROPOSICIÓN DE LEY. 6.- ENMIENDAS PRESENTADAS POR LOS GRUPOS PARLAMENTARIOS A LA PROPOSICIÓN DE LEY. 7.- LA CUESTIÓN SIMBÓLICA: LA VECINDAD CIVIL COMO INSTRUMENTO DE GARANTÍA DE IDENTIDAD DE UN PUEBLO. 8.CONCLUSIONES. 9.- BIBLIOGRAFÍA.

\section{INTRODUCCIÓN}

El Boletín Oficial de las Cortes Generales publicó el 9 de septiembre de 2016 una Proposición de Ley, presentada por las Cortes de Aragón, por la que se modifica el Código Civil en relación con el estatuto personal y vecindad civil (Proposición de Ley). Tras la toma en consideración de la Proposición de Ley el 15 de noviembre de 2016, se debatió por renombrados juristas y diputados de todos los partidos políticos, tal y como se refleja en los Diarios de sesiones de la Comisión de Justicia del Congreso de los Diputados de los días 22 de febrero, 9 de marzo y 4 de abril de 2017. Gracias a este debate volvieron a ponerse sobre la mesa las diferentes opiniones doctrinales que existen hoy en día sobre determinados aspectos de la vecindad civil, institución tan relevante como característica de nuestro sistema plurilegislativo ${ }^{2}$, pero a la vez tan desconocida para el ciudadano lego en Derecho que no será consciente de que, en determinadas situaciones vinculadas a su persona, la aplicación de uno u otro Derecho civil dependerá, en gran medida, de la vecindad civil que ostente.

* Este trabajo se enmarca en la ejecución del proyecto de investigación «Balance de 38 años de plurilegislación civil postconstitucional: situación actual y propuestas de futuro», financiado por el Ministerio de Economía y Competitividad y el FEDER [Ref. DER201677190-R]. Me gustaría expresar mi agradecimiento a quienes anónimamente revisaron la contribución y la mejoraron con sus comentarios, a los profesores S. ÁLVAREZ GonzÁLEZ, M.P. GARCíA RUBio y M. OTERo CRESPO, por su paciencia y tiempo dedicado a explicarme cuestiones y pulir lo escrito, y a los ponentes del Seminario «El Derecho interregional español: ¿una urgente reforma?», organizado por De Conflictu Legum, estupenda primera toma de contacto con este tema.

2 O. Casanovas y La Rosa, "Art. 16.1. CC", El nuevo Título Preliminar del Código y la Ley de 2 de mayo de 1975, Tecnos, Madrid, 1977, p. 739, ha señalado la semejanza de esta institución con la Heimatzuständigkeit del antiguo imperio austro-húngaro. También llamada Heimatrecht («Ley de la patria») era el término utilizado para la conexión personal a un determinado municipio, y podía adquirirse por inscripción en el registro del lugar, por residencia después de diez años, por matrimonio o por descendencia. Además, se podía perder por la ausencia de más de dos años de determinado territorio. En 1939 la Heimatrecht fue suprimida, y a partir de 1945 se comenzó a utilizar el Staatsbuergerschaftsnachweis (certificado de ciudadanía). Sobre el término Heimatsrecht, vid. https://austria-forum.org/af/AEIOU/Heimatrecht/Heimatrecht_english 
La hoy unánimemente Ilamada vecindad civil (otrora «regionalidad» o «ciudadanía foral») ${ }^{3}$ se ha definido como la circunstancia personal de los nacionales españoles que determina la aplicabilidad, en cuanto ley personal suya ${ }^{4}$, del Derecho del Código Civil o de uno de los Derechos civiles autonómicos o forales ${ }^{5}$. El Derecho interregional ha basado la aplicación de la ley personal en la noción de vecindad civil (art. 16.1.1.a CC) $y$, a este fin, ha establecido un régimen legal específico de su atribución, adquisición y pérdida (arts. 14 y 15 CC), diciendo el art. 14.1 CC que la sujeción al Derecho civil común o al especial o foral se determina por la vecindad civil.

Sin embargo, la doctrina más autorizada señala que la anterior declaración no es más que un punto de partida, un principio, pues realmente serán las reglas de Derecho internacional privado (DIPr.) las que tengan la última palabra sobre la relevancia de la vecindad civil. Y ello porque el art. $16.1 \mathrm{CC}$, al establecer que los conflictos de leyes se resolverán según las normas de Derecho internacional privado con la particularidad, en primer lugar, de que «será Ley personal la determinada por la vecindad civil», está aparejando la suerte de la vecindad civil a la de la nacionalidad en DIPr. Y la nacionalidad, como criterio identificador de la ley aplicable, está perdiendo peso, inclinándose más la balanza hacia otros como la autonomía de la voluntad o la idea de vínculo más estrecho ${ }^{6}$. Esta premisa será fundamental a la hora de entender algunas de las posturas vertidas en las comparecencias de los expertos en el Congreso de los Diputados durante el debate sobre la Proposición de Ley, que más adelante comentaremos.

Si bien la Proposición de Ley no se ha aprobado, la sola lectura de las opiniones tan divergentes que manifestaron los expertos comparecientes y de las enmiendas que posteriormente se presentaron muestra lo profundo que puede resultar el debate no solo de ciertos aspectos de esta institución, sino también, y a pesar de su relevancia, de su existencia misma, en gran parte debido a la citada influencia que el DIPr ejerce sobre ella.

Lo que los aragoneses están proponiendo no es una reforma al conjunto de la regulación de la vecindad civil, por lo que tampoco entrará dentro de

\footnotetext{
3 Sobre el término «vecindad civil», DE CASTRO veía como grave defecto que no era verdadera vecindad, «pues ni da, ni quita, ni se basa en la condición de vecino». Aun así, este autor descartará otras denominaciones como «regionalidad», «provincialidad civil»o «ciudadanía foral» y utilizará la de «vecindad civil» con base en las alusiones del Código civil a ella, así como del Real Decreto de 12 de junio de 1899 que, entre otras cosas, sustituye el libro de ciudadanía del Registro civil por el libro de «Ciudadanía y de vecindad civil». F. De CASTRO y Bravo, Derecho civil de España, Civitas, Madrid, 1952, p. 468.

${ }^{4}$ Y la ley personal, según el art. $9.1 \mathrm{CC}$, es la que rige la capacidad y el estado civil, los derechos y deberes de familia y la sucesión por causa de muerte.

5 J. Delgado ECheverría, "Comentarios a los artículos 14 y 15 CC", Comentarios al Código civil, I, Título preliminar, J. RAMS AlBeSA, (Coord.), Bosch, Barcelona, 2000, p. 393.

${ }^{6}$ S. Álvarez GonzÁlez, "Domicilio, vecindad civil y nacionalidad", Tratado de Derecho de la persona física, Tomo II, M.C. Gete-Alonso y CAlerA, (Dir.), Civitas-Thomson Reuters, Navarra, 2013, pp. 340-341.
} 
nuestras pretensiones dar una visión global de tan compleja institución. Las modificaciones al régimen de la vecindad civil propuestas por las Cortes de Aragón afectan básicamente a la forma de adquisición, así como a una posible recuperación de la vecindad civil perdida, por lo que nos limitaremos a hacer un breve barrido por las formas de atribución, adquisición, conservación, pérdida y recuperación de la vecindad civil para a continuación exponer los argumentos dados en apoyo bien a la reforma, bien al mantenimiento del texto vigente, y que interpelarán no solo a la técnica legislativa, sino también a su dimensión simbólica o de sentimiento de pertenencia a un determinado lugar?

\section{UNA CUESTIÓN PREVIA: LA COMPETENCIA EXCLUSIVA DEL ESTADO SOBRE EL RÉGIMEN JURÍDICO DE LA VECINDAD CIVIL}

El tan controvertido art. $149.1 .8^{a} \mathrm{CE}^{8}$ atribuye competencia exclusiva al Estado para dictar las normas para resolver los conflictos de leyes internos. En este sentido, ÁlvAREZ González reivindicaba el carácter estrictamente cerrado de la competencia exclusiva del Estado en materia de normas para la resolución de los conflictos de leyes, concluyendo que no puede existir una «especie de competencia secundaria y complementaria de las Comunidades Autónomas», lo que considera que sucede con normas de estos derechos civiles autonómicos que «autolimitan el ámbito de aplicación de su normativa civil»» ${ }^{9}$. Normas que,

7 Sobre el valor simbólico de la vecindad civil, vid. J. DELGADO ECHEVERRÍA, "Vecindad civil
y derecho interregional privado: una reforma necesaria", Lección inaugural de la apertura
de curso de la Academia Vasca de Derecho, pronunciada el 25 de octubre de 2017 en la
sede del Colegio Notarial del País Vasco, p. 9. Este autor entiende que la vecindad civil
apela a los afectos y a las identidades colectivas, hasta el punto de que cuando surgió a
finales del S. XIX dicha institución, se hizo de ella «la más conspicua de las diferencias en
el Derecho entre los ciudadanos del unitario y centralista Estado español». También PuIG
FERRIOL habla de la influencia que tienen los «factores políticos, sentimentales o como se
les quiera Ilamar» y que enturbian el enfoque estrictamente jurídico de la institución,
haciendo problemáticos los acuerdos sobre cuestiones de adquisición y pérdida de la
vecindad civil. L. PuIG FERRIOL, en el prólogo al libro de I. RIBAS ALGUERÓ, La vecindad civil:
problemática en torno a su régimen jurídico y a su prueba, Bosch, Barcelona, 1984, p.
VII.

8 Sobre el artículo 149.1. $8^{a}$ CE, norma básica de distribución de competencias normativas en materia de Derecho civil entre el Estado y las Comunidades Autónomas, han corrido ríos de tinta. Entre los últimos trabajos sobre el tema destacamos el de M.P. GARCía RuBio, "Presente y futuro del Derecho civil español en clave de competencias normativas", Revista de Derecho Civil, vol. IV, núm. 3 (julio-septiembre, 2017), Estudios, pp. 1-33, quien muy sensatamente señala dos posibles vías de solución al eterno y complejo conflicto competencial en materia de Derecho civil. En síntesis, la primera pasaría por que el Tribunal Constitucional «cesase en su empeño de banalizar la situación legislativa real existente en muchas Comunidades Autónomas», careciendo de sentido «seguir anclados en la añeja idea de la "conexión suficiente"»; la segunda vía consistiría en la modificación del actual modelo territorial a través de la reforma constitucional, vistos «los síntomas de agotamiento del [mismo]».

${ }^{9}$ S. Álvarez González, Estudios de Derecho interregional, De Conflictu Legum, Estudios de Derecho internacional privado, núm. 9, Santiago de Compostela, 2007, pp. 13 y 1543. Sintéticamente, significa, cogiendo el ejemplo del autor, que si el sistema de Derecho interregional determina que se aplique el Derecho aragonés, este no puede en un segundo plano decidir si se aplica o no. Y ello porque, p. 37, «la validez de una norma 
sorprendentemente, en su mayoría no han sido declaradas inconstitucionales, y que siguen mencionándose incluso en la Proposición de Ley comentada, cuando en el punto segundo de su exposición de motivos hace alusión al art. 9.2 del Estatuto de Autonomía de Aragón, que dice que «el Derecho Foral de Aragón tendrá eficacia personal y será de aplicación a todos los que ostenten la vecindad civil aragonesa, independientemente del lugar de su residencia y excepción hecha de aquellas disposiciones a las que legalmente se les atribuya eficacia territorial» ${ }^{10}$.

Que el Estado tenga competencia exclusiva en esta materia tiene la consecuencia de que el sistema conflictual interno será único y uniforme, lo que no sucedería si cada Comunidad Autónoma con Derecho civil propio tuviese competencia para ello ${ }^{11}$, pues si bien las respuestas conflictuales múltiples podrían ser más conformes con las instituciones, el nivel de complejidad de los supuestos sería mayor al no disponer ya de esa

medida en términos de competencia no depende de la coherencia o compatibilidad de su consecuencia jurídica con la norma competente, sino de la materia regulada (supuestos de hecho) para la que se posee competencia, o no». También J. L. IRIARTE ÁNGEL, "Ámbito material y personal y normas conflictuales", El Derecho civil vasco del siglo XXI. De la ley de 2015 a sus desarrollos futuros, Colección informes y documentos serie maior del Parlamento Vasco, Bilbao, 2016, p. 143, interpretando la doctrina de la STC de 23 de abril de 2013, dice que las Comunidades Autónomas no pueden dictar normas de extensión o normas materiales especiales para regular los conflictos de leyes internos. No obstante, como señala M. E. ZABALO ESCUDERO, "Autonomía de la voluntad, vecindad civil y conflictos de leyes internos", Autonomía de la voluntad en el derecho privado: Estudios en conmemoración del 150 aniversario de la Ley del Notariado, L. PRATS AlBentosA (Coord.) Vol. 5, 2012, pp. 408 y ss., la realidad demuestra que sí existen estas normas de conflicto en los ordenamientos autonómicos, encontrando su razón de ser bien en la tradición histórica, bien por la convivencia de derechos civiles distintos en su ámbito territorial, o bien por desarrollar materias que son de nueva regulación o carecen de respuesta en la legislación estatal, como sucede con la regulación de las parejas de hecho o de la custodia compartida.

10 Disposiciones como esta, que prescriben la eficacia territorial del propio Derecho civil autonómico, son las que están generando, en palabras de ÁlvAREZ GoNZÁLEZ, que hoy en día exista cierta práctica en los tribunales españoles de aplicar la ley «propia» del territorio en el que actúa dicho tribunal. Por ejemplo, si está conociendo un juez catalán, aplicará la ley catalana. S. Álvarez GonzÁLEz, "Cuestiones de Derecho interregional en la aplicación de los nuevos reglamentos comunitarios", versión escrita, pendiente de publicación, de la participación en la mesa redonda bajo el mismo título que tuvo lugar el 20 de marzo de 2018, en la sede del Colegio de Notarios de Cataluña, a la que he tenido acceso por gentileza del autor, p. 19. Del mismo autor, centrándose en esta práctica, vid. "La «eficacia territorial» del Derecho civil autonómico como (no) criterio de aplicación en situaciones internacionales", Revista de Derecho Civil, vol. IV, núm. 3, 2017, pp. 35-62.

${ }^{11}$ De hecho, F. DE CASTRO y BRAvo, Derecho civil... op.cit., p. 470, se refiere a la «especie de comedia de equívocos» que hubo con los trabajos preparatorios del CC y su primera edición, cuyos artículos 12 y 15 tuvieron que ser modificados, pues su aplicación llevaba a resultados contradictorios, haciendo que una persona resultase sometida tanto al Código Civil como a algún Derecho foral. Por ello la segunda edición del CC redactó de nuevo el art. 15 (lo que hoy sería, con modificaciones, el art. $14 \mathrm{CC}$ ) que impuso una regulación uniforme, «imprescindible para resolver conforme a unas mismas reglas los conflictos interlocales de leyes». Entendemos que DE CASTRO, al utilizar la palabra «interlocal», está haciendo alusión a los conflictos interregionales más que interlocales. 
armonía $^{12}$. Esta es la razón de que las Cortes de Aragón no tengan competencia para modificar el régimen de la vecindad civil sino es a través de la figura de la Proposición de Ley remitida al Congreso de los Diputados $^{13}$. De hecho, cuando las Comunidades Autónomas han intentado regular ellas mismas algún aspecto de esta institución, la respuesta del TC ha sido clara: sirva de ejemplo la sonada STC $156 / 1993^{14}$ en la que se declaró inconstitucional el art. 2 de la Ley 8/1990, que daba nueva redacción al art. 2, párrafo primero, de la Compilación de Derecho civil de Baleares ${ }^{15}$. El precepto fue declarado inconstitucional al entenderse que se estaba sustituyendo a la vecindad civil por la residencia como criterio determinante para la aplicación del Derecho común o del foral, ampliando el ámbito de aplicación del derecho civil de las islas al introducir un punto de conexión distinto, cuál era la residencia en territorio balear (FJ $3^{\circ}$ ).

El Tribunal Constitucional ha seguido manifestándose reiteradamente sobre lo que implica esta reserva competencial exclusiva a favor del Estado, estableciendo en una de sus últimas sentencias sobre el tema, la de 23 de abril de 2013, que la reserva del art. 149.1.8 ${ }^{\text {a }}$ Implicaba que se integraba en todo caso en ella la adopción de las normas de conflicto y la definición de cada uno de sus elementos, entre los que cuenta, y con mayor relevancia, la determinación de los puntos de conexión que llevan a la aplicación, en supuestos de tráfico jurídico interregional, de uno de los ordenamientos civiles que coexisten en España» ${ }^{16}$.

\footnotetext{
12 J.L. IRIARTE ÁNGEL, "Ámbito material y personal...", op.cit., p. 140.

${ }^{13}$ La potestad de remitir proposiciones de ley a la Mesa del Congreso de los Diputados por parte de las Asambleas de las Comunidades Autónomas está prevista expresamente en el art. 87.2 CE. Esta es una de las manifestaciones más singulares de la participación de los órganos autonómicos en la formación de la voluntad legislativa estatal, expresión de la fundamental cooperación que debe haber en un Estado descentralizado y plurilegislativo como el nuestro. Es, a su vez, prueba de los principios de unidad y autonomía, pues si bien la aprobación de la ley corresponderá a las Cortes Generales y no a la asamblea proponente, un objetivo lógico al que tenderán las proposiciones será a la defensa de los intereses de la población representada por dicha asamblea. J. J. LAVILLA RUBIRA, "Las proposiciones de Ley remitidas por las Comunidades Autónomas al Congreso de los Diputados", Revista Española de Derecho Constitucional, Año 10, núm. 28, eneroabril 1990, pp. 9 y 14-15. En el caso concreto de Aragón, el art. 292 del Reglamento de las Cortes de Aragón prevé que la Cámara autonómica pueda tanto solicitar del Gobierno español la adopción de proyectos de ley, como remitir al Congreso proposiciones de ley sobre cualquier materia de política general.

${ }^{14}$ STC 156/1993, de 6 de mayo (RTC \1993\156).

${ }^{15}$ El art. 2. 1 citado decía que «Las normas del Derecho Civil de Baleares tendrán eficacia en el territorio de la Comunidad Autónoma y serán de aplicación a quienes residan en él sin necesidad de probar la vecindad civil. Se exceptúan los casos en que, conforme al Derecho interregional o internacional privado, deban aplicarse otras normas».

16 STC 93/2013, de 23 de abril de 2013 (RTC 2013/93), resolviendo el recurso de inconstitucionalidad presentado contra la Ley Foral del Parlamento de Navarra 6/2000, de 3 de julio, para la igualdad jurídica de las parejas estables. Con anterioridad, las sentencias más importantes sobre la reserva competencial a favor del Estado para dictar normas para resolver los conflictos de leyes fueron las SSTC 72/1983, de 29 de julio (RTC 1983/72), 156/1993, de 6 de mayo (RTC 1993/156) y 226/1993, de 8 de julio (RTC 1993/226).
} 
Hoy estos razonamientos del TC podrían sembrarnos la duda sobre la (in)constitucionalidad de preceptos de leyes autonómicas como la Disposición Transitoria Séptima de la Ley 5/2015, de 25 de junio, de Derecho civil vasco (Ley 5/2015). Esta disposición, titulada «atribución de la vecindad civil vasca», establece que «Desde la entrada en vigor de esta ley, quienes gocen de la vecindad civil en cualquiera de los territorios de la Comunidad Autónoma del País Vasco, adquirirán automáticamente la vecindad civil vasca y la vecindad civil local que, en su caso, les corresponda». Esta disposición, conjugada con el art. 10.1 de la misma ley, «el Derecho civil de la Comunidad Autónoma del País Vasco se aplica a todas aquellas personas que tengan vecindad civil vasca», origina serias dudas sobre su constitucionalidad, pues los que ostentaban la vecindad civil común a la entrada en vigor de la Ley $5 / 2015$, pasan a tener la vecindad civil vasca y por tanto quedan sometidos al Derecho civil vasco ${ }^{17}$. Y, asimismo, quienes tenían vecindad civil en un territorio foral del País Vasco, seguirán rigiéndose por el Derecho foral que les corresponda pero, en lo no previsto por este, por el Derecho civil vasco (y no por el del Código civil, como sucedía antes). Aunque no se está diciendo literalmente que «quienes residan» en el País Vasco pasarán a tener vecindad civil vasca, de facto es lo que se está consiguiendo. La pregunta es si se está vulnerando, por tanto, el art. 149.1.8 $\mathrm{CE}$.

Incluso podríamos preguntarnos si la vulneración al tan controvertido y glosado art. 149.1.8 ${ }^{\text {a }}$ CE podrá venir (también) debido a que el País Vasco está regulando las normas para resolver los conflictos de leyes interlocales ${ }^{18}$. La cuestión es si la competencia exclusiva del art. 149.1.8 a CE comprende las normas para resolverlos. Si partimos del art. $15.4 \mathrm{CC}^{19}$ vemos que se somete al mismo régimen que la vecindad civil la «dependencia personal respecto a una comarca o localidad con especialidad civil propia o distinta, dentro de la legislación especial o foral del territorio correspondiente». Por tanto, de un primer análisis del artículo cabría deducir que es el Estado quien tiene esta competencia. Sin

17 En la SAP de Álava 360/2018 20 de julio (JUR 2018\306945), es determinante este cambio de vecindad civil. La sentencia trata el caso de un testador que dispone su herencia en favor de sus nietos, excluyendo al hijo y tío de los herederos, en un momento en el que ostentaba la vecindad civil común. No obstante, fallece una vez que entra en vigor la Ley 15/2015, la cual prevé en su art. 51.1 el apartamiento y preterición de legitimarios ( El causante podrá disponer de la legítima a favor de sus nietos o descendientes posteriores, aunque vivan los padres o ascendientes de aquél»). Por ello, el Tribunal declara plenamente eficaz la disposición testamentaria impugnada por el hijo (FJ $3^{\circ}$ ).

18 Que son aquellos suscitados entre los ordenamientos locales o comarcales pertenecientes a una misma Comunidad Autónoma.

${ }_{19}$ Este apartado del art. 15 CC fue introducido por el Decreto de 31 de mayo de 1974, que dio nueva redacción a los arts. 14 y 15 CC de acuerdo con la Ley de 17 de marzo de 1973, de Bases para la modificación del Título Preliminar del Código Civil, y que no hizo más que generalizar la norma que ya se contenía en las Compilaciones de Vizcaya y Álava (art. 5: «La vecindad local se determinará por las normas generales que regulen la ciudadanía y vecindad civil») y Cataluña (art. 3.2.: «La vecindad local se regirá por las normas que rigen la vecindad civil»). Al respecto, vid. J. DeLGADo ECHEVERRía, "Comentarios a los artículos...", op.cit., p. 398. 
embargo, tras la entrada en vigor de la Constitución la doctrina parece inclinarse hacia la permisión de que sea el legislador autonómico el competente ${ }^{20}$, apoyándose en que la vecindad local solo es accesible a quien ya tiene la vecindad correspondiente a un Derecho civil autonómico. Concretamente, al tratar la situación en el País Vasco, se argumenta que según el artículo 10.5 de su Estatuto de Autonomía ${ }^{21}$, tiene competencia exclusiva para fijar el ámbito territorial de vigencia de los distintos ordenamientos civiles que conviven dentro de su territorio ${ }^{22}$.

En definitiva, y en tanto no se manifieste el Tribunal Constitucional sobre estas dos cuestiones concernientes a la Ley 5/2015, conviene ser prudentes $^{23}$, y más cuando nadie las ha planteado a día de hoy ante el tribunal, argumento que utilizan en la jurisprudencia menor cuando se plantea esta cuestión ${ }^{24}$; aunque lo cierto es que las previsiones de esta ley, en especial la atribución de una nueva vecindad civil vasca a quienes carecían de ella, no dejan de ser cuando menos algo anómalas.

Volviendo a la iniciativa aragonesa, el hecho de que el art. 149.1.8 ${ }^{a} \mathrm{CE}$ atribuya al Estado esta competencia, implicará que de tenerse en cuenta, se reforme el Código civil y se aplique, «lógicamente, al resto de comunidades autónomas de nuestro país, universalizando esta iniciativa

${ }^{20}$ En este sentido es clara M. A. PARRA LUCÁN, "Comentarios a los artículos 14 y 15 CC", Código civil comentado, R. Valpuesta Fernández, / P. De Pablo Contreras, / A. Cañizares LASO, / J. ORduña MORENo (Dirs.), Civitas - Thomson Reuters, Cizur Menor (Navarra), 2016, p. 183, para quien el art. $15.4 \mathrm{CC}$ ha de considerarse supletorio de la normativa autonómica sobre este punto. No es tan tajante J. Delgado ECHEVERRÍA, "Comentarios a los artículos...", op.cit., p. 398, para quien «no es seguro que la materia (...) sea ahora [tras la Constitución, los Estatutos de Autonomía, y cierto desarrollo de los derechos civiles autonómicos], de competencia exclusiva del Estado».

${ }^{21}$ Ley Orgánica 3/1979, de 18 de diciembre, de Estatuto de Autonomía para el País Vasco. BOE de 22 de diciembre de 1979. Su art. 10.5 dice que «La Comunidad Autónoma del País Vasco tiene competencia exclusiva en las siguientes materias: (...) 5. Conservación, modificación y desarrollo del Derecho Civil Foral y especial, escrito o consuetudinario propio de los Territorios Históricos que integran el País Vasco y la fijación del ámbito territorial de su vigencia».

22 La doctrina defensora de esta idea se ha apoyado en el Dictamen del Consejo de Estado con expediente No 1537/92, Relativo a la adecuación al orden de competencias derivado de la Constitución y del Estatuto de Autonomía del País Vasco de la Ley 3/1992, de 1 de julio, del Derecho Civil Foral), en el que se consideró que «tales normas resultan necesarias para la aplicación del propio Derecho Foral y presuponen el régimen general común, por lo que no infringen el orden constitucional de competencia». Consejo de Estado. Recopilación de doctrina legal, 1993, pp. 66-92.

23 Desde esta prudencia se expresa J. L. IRIARTE ÁNGEL, "Ámbito material y personal...", op.cit., p. 154, diciendo que «solamente una futura decisión del Tribunal Constitucional puede fijar y aclarar tan espinoso problema», si bien esta reflexión es anterior a la citada ley $5 / 2015$.

${ }^{24}$ Así se refleja en mencionada SAP de Álava 360/2018 20 de julio (JUR 2018\306945), en la que el recurrente había puesto de relieve las dudas doctrinales que la Ley 5/2015 suscita en cuanto a la regulación de la "vecindad civil vasca", pudiendo infringir la competencia exclusiva del Estado regulada en el art. 149.1.8 CE; a lo que el Tribunal responde que no consta que haya ningún recurso o cuestión de inconstitucionalidad sobre este tema, por lo que desestima el motivo alegado (FJ $\left.4^{\circ}\right)$. Lo cierto es que la propia Audiencia podría haber planteado tal cuestión de haber tenido dudas de constitucionalidad, pero tampoco consta que lo haya hecho. 
aragonesa para todos los españoles», en palabras de uno de los diputados participantes en el debate de la Proposición de Ley ${ }^{25}$. Pero antes de pasar al análisis de la misma, acometeremos un breve barrido por el régimen jurídico de la vecindad civil.

\section{BREVES NOTAS SOBRE LA ATRIBUCIÓN, ADQUISICIÓN, CONSERVACIÓN, PÉRDIDA Y RECUPERACIÓN DE LA VECINDAD CIVIL}

Como expusimos anteriormente, la Proposición de Ley se refiere exclusivamente a cuestiones que afectan a la forma de atribución y adquisición de la vecindad civil, así como a una posible recuperación de la vecindad civil perdida. La clasificación que consideramos más acertada sobre el régimen de atribución y adquisición de la vecindad civil es aquella que distingue entre su determinación por (1) filiación y nacimiento, (2) elección por los progenitores o por el propio interesado y (3) residencia ${ }^{26}$. Al mismo tiempo, se habla de un régimen de conservación, pérdida y recuperación de la vecindad civil. Esta clasificación nos permite recurrir a una analogía con aquella prevista para el régimen jurídico de la nacionalidad, y que distingue entre su atribución ${ }^{27}$ por filiación (ya sea por naturaleza o adopción plena) o nacimiento en España; su adquisición por opción o por naturalización (pudiendo ser por Carta de Naturaleza o por residencia), su pérdida y su recuperación ${ }^{28}$.

\subsection{Atribución por filiación y nacimiento}

En primer lugar, el art. 14.2 CC establece una adquisición por iure sanguinis: «tienen vecindad civil en territorio de Derecho común o en uno de los de Derecho especial o foral, los nacidos de padres que tengan tal vecindad». Por tanto, ambos progenitores deben ostentar igual vecindad para que el hijo la obtenga, cuestión que quedó clara tras la reforma operada en este artículo por la Ley $11 / 1990$, de 15 de octubre ${ }^{29}$. Esta ley eliminó, por fin, la preferencia que había por la vecindad del padre frente

25 O. Galeano Gracia, en su comparecencia en la toma en consideración de la Proposición de Ley. Diario de sesiones del Congreso de los Diputados, 15 de noviembre de 2016, p. 15.

${ }^{26}$ Esta es la seguida por S. Álvarez GonzÁlez, "Domicilio, vecindad civil...", op.cit., pp. 351-358. Otras clasificaciones distinguen entre adquisición originaria, por opción y por residencia. J. Delgado ECheVerRía, "Comentarios a los artículos...", op.cit., p. 398.

27 No es baladí la distinción entre «atribución» y «adquisición» de la nacionalidad, pues como bien señalan J. C. FERnÁndez RozAs / P. RodríGUez MATEOS, Derecho español de la nacionalidad, Tecnos, Madrid, 1987, p. 133 (nota a pie 2), la primera no necesita de la autonomía de la voluntad, actuando la nacionalidad directamente. En cambio, la autonomía de la voluntad es del todo relevante en los procesos de adquisición de la nacionalidad española. Análogamente, podremos decir lo mismo sobre los regímenes de atribución o adquisición de la vecindad civil.

28 J. C. Fernández Rozas / S. Álvarez GonzÁlez, "Derecho español...", op.cit., pp. 133-234.

29 J. Delgado Echeverría, "Artículo 14", Comentarios a las reformas del Código civil. Desde la Ley 21/1987, de 11 de noviembre, a la Ley 30/1991, de 20 de diciembre, R. Bercovitz Rodríguez-Cano (Coord.), Tecnos, 1993, p. 506, consideró que, si bien la eliminación de esta regla (junto con la que establecía que la mujer seguiría la condición del marido) se retrasó mucho más de lo deseado, fue el mayor logro de la ley 11/1990. 
a la de la madre, y debido a que no estableció efectos retroactivos ni dispuso transitoriamente un régimen para estos supuestos, surgió la duda de si afectaría a los nacidos entre la entrada en vigor de la Constitución española, el 29 de diciembre de 1978, y la de la Ley 11/1990, el 7 de noviembre de $1990^{30}$. Esta cuestión ya ha sido aclarada por la jurisprudencia, que ha establecido la inconstitucionalidad sobrevenida del precepto, por lo que los efectos se retrotraen a la entrada en vigor de la Constitución ${ }^{31}$.

En segundo lugar, se determina la adquisición de vecindad por el lugar de nacimiento o iure soli de una forma residual (art. $14.3 \mathrm{CC}$ ) pero con bastante importancia en la práctica, dado que serán muchos los progenitores que ostenten distintas vecindades y pocos los que, entre ellos, decidan prever específicamente frente al encargado del Registro Civil la vecindad elegida para el hijo o hija. Sobre este último extremo, por ahora se sigue negando que la declaración pueda ser ante Notario, aunque ya hay voces que verían factible, en un futuro próximo, un cambio de criterio, vistas las amplias funciones que se les están atribuyendo a

\footnotetext{
30 Así lo expresaba J. Delgado ECheVerRíA, "Comentarios a los artículos...", op.cit., p. 399.

${ }^{31}$ El antiguo art. 14.4 CC (en su redacción de 1974 y hasta la promulgación de la citada ley de 1990), decía que «La mujer casada seguirá la condición del marido, y los hijos no emancipados, la de su padre, $y$, en defecto de éste, la de su madre». El Tribunal Supremo, en su STS 588/2009, de 14 septiembre (RJ\2009\4445), en un caso que discutía la vecindad de la mujer casada, declaró la inconstitucionalidad sobrevenida de este precepto, lo que entendemos que también afecta al caso de que fuese la vecindad de los hijos la cuestionada. En relación con esta materia, el Tribunal Constitucional ya se había pronunciado en su STC 39/2002, de 14 de febrero (RTC 2002\39), declarando inconstitucional el art. 9.2 CC (en su redacción de 1974) en relación a la ley nacional del marido como punto de conexión para determinar el régimen económico matrimonial en los matrimonios de distinta vecindad civil. Lo cierto es que, como bien dice la STS $588 / 2009$ comentada, hubo una «falta de diligencia del legislador» en la regulación de esta materia, poniendo de relieve que «la derogación del denominado principio de unidad familiar en la vecindad civil, en cuya virtud la ley del marido determinaba la de la esposa y la de los hijos in potestate, se mantuvo hasta la reforma efectuada en 1990; sin embargo, la ley 14/1975, de 2 de mayo ya excluyó la comunicación a la mujer casada de la nacionalidad española que adquiría su marido (Art. 21 CC, redactado por ley 14/1975)» (FJ 40). Como recoge S. Álvarez GonzÁlezZ, "Domicilio, vecindad civil...", op.cit., p. 355, la doctrina sí se planteó la incidencia de esta regla, aun relativa a la nacionalidad, sobre la materia de la vecindad civil, pero la idea de la derogación tácita del art. 14.4 CC no se adoptó. A día de hoy la declaración de inconstitucionalidad del precepto sigue alcanzando solo hasta 1978, pues así lo ha declarado reiteradamente la jurisprudencia en casos donde la vecindad civil discutida tiene su causa en matrimonios celebrados antes de la entrada en vigor de la Constitución (véase, por ejemplo, la SAP de las Islas Baleares 542/2002, de 10 septiembre (JUR 2002 (272157), en la se dice en su FJ $2^{\circ}$ que «pese a tan indiscutible actual reproche a aquellas normas, no es menos cierto, tal y como vino a considerar la sentencia del Tribunal Supremo, Sala $1^{\text {a }}$, de 6.10.86 (RJ 1986\5327), que hallándonos ante un matrimonio celebrado en fechas anteriores a la Constitución, resulta digno de mejor protección jurisdiccional el postulado de inmutabilidad del régimen económico matrimonial configurado antes de la promulgación del actual texto fundamental»).
} 
estos profesionales jurídicos tras la Ley 15/2015, de 2 de julio, de jurisdicción voluntaria ${ }^{32}$.

Por último, como regla subsidiaria de segundo grado se prevé la atribución de la vecindad de derecho común (art. 14.3.I in fine). A favor del precepto se ha dicho que este criterio subsidiario tiene la virtud de la simplicidad, ya que cubre todos los supuestos imaginables ${ }^{33}$. Pero no han sido pocos los autores que han discutido la posible inconstitucionalidad de la norma, al considerarse que se le estaba dando preferencia a una de las vecindades frente al resto, lo que chocaría con el principio de igualdad entre todos los ordenamientos civiles ${ }^{34}$. Esta cuestión quedó zanjada tras la STC 226/1993, de 8 de julio, que sorprendentemente consideró que tanto el art. $14.3 \mathrm{CC}$, párrafo $1^{\circ}$ in fine como el art. $16.3 \mathrm{CC}$ párrafo primero, que también había sido impugnado, eran compatibles con la Constitución. $Y$ ello porque aunque en principio debía velarse por soluciones generales y abstractas en la aplicación de los diversos regímenes civiles, existía un límite: el de la seguridad jurídica o, en palabras del Tribunal Constitucional, «preservar la certeza en el tráfico privado interregional» ${ }^{35}$. No obstante, entendemos que esta preferencia carece de toda justificación si se atiende al principio de igualdad entre todos los derechos civiles españoles que debe presidir esta materia, por lo que se debería de haber optado por otras soluciones, como podría ser la asignación de la vecindad civil más estrechamente vinculada o la elección por los progenitores o por el juez en caso de desacuerdo de estos últimos ${ }^{36}$.

\subsection{Elección por los progenitores o por el propio interesado}

Es la forma de adquisición derivada de una declaración unilateral de voluntad bien de los progenitores, bien del sujeto legitimado para ella. Por

\footnotetext{
32 M. A. PARRA LuCÁn, "Comentarios a los artículos...", op.cit., p. 173, en donde la autora estima que, «dada la amplitud de funciones que se atribuye a este cuerpo en otras materias, en particular en las modificaciones del Código civil y la LRC 2011 operadas por la Ley $15 / 2015$, de 2 de julio, de la jurisdicción voluntaria, habrá que esperar a ver si tal criterio se mantiene en el futuro». Sobre la importancia del Notario a la hora de dar solución a supuestos en los que concurren varios elementos sujetos a leyes civiles españolas distintas, se manifiesta A. CALATAYUD, "La unidad del derecho interregional", Revista del Colegio Notarial de Madrid, núm. 37, mayo-junio 2011, p. 132, diciendo que «no sería exagerado afirmar que el Notariado es un elemento esencial para articular la pluralidad legislativa civil en España, ya que el control que el Notario ejerce en el momento de otorgamiento produce que le sea aplicada al acto o contrato jurídico la ley que realmente le corresponde, evitando una conflictividad que podría ser mucho mayor a la vista del extraordinario número de supuestos que hay en la práctica con elementos territoriales diversos».

33 R. Bercovitz Rodríguez-Cano, "Arts. 13, 14 y 15", Comentarios al Código Civil, R. Bercovitz Rodríguez-Cano (Dir.), Thomson-Aranzadi, Cizur Menor (Navarra), 2006, p. 108.

34 En este sentido, J. Delgado EcheVerría, "Comentarios a los artículos...", op.cit., p. 403; S. Álvarez GonzÁlez, "Derecho interregional...", op.cit., pp. 348 y ss.

35 S. Álvarez GonzÁlez, "Domicilio, vecindad...", op.cit., p. 350, hace un análisis más detallado de la sentencia.

${ }^{36}$ En este sentido, S. Álvarez González, "Domicilio, vecindad...", op.cit., pp. 352-353.
} 
un lado, se permite que cuando los progenitores tengan distinta vecindad, puedan decidir en un plazo de seis meses cuál de ellas atribuirle al hijo (art. 14.3.II CC). Por otro lado, el hijo, desde cumplidos los catorce años y hasta un año después de su emancipación, puede optar por la vecindad civil de su lugar de nacimiento o por la última que ostentasen cualquiera de sus progenitores (art. 14.3.IV CC). Este será uno de los puntos a tratar en la Proposición de Ley, queriéndose ampliar la facultad de opción del hijo.

Finalmente, también se permite que el cónyuge no separado pueda optar por la vecindad civil del otro, en aras al principio de unidad familiar (art. 14.4 CC), y en contraposición a la regla anterior a la reforma operada por la Ley $11 / 1990$, de 15 de octubre, que establecía que la mujer seguiría la condición del marido ${ }^{37}$.

\subsection{Adquisición por residencia}

El art. 14.5 CC permite dos maneras de adquisición de la vecindad civil por residencia: la primera de ellas, tras dos años de permanencia en un determinado lugar, y siempre que el interesado manifieste ser esa su voluntad. La segunda, transcurridos diez años y sin declaración en contrario, se adquirirá la vecindad del lugar en el que se haya permanecido esos diez años. Por tanto, vemos que la principal diferencia entre ambos modos de adquisición es, además del tiempo transcurrido, que mientras que en la primera se necesita una declaración expresa de voluntad, en la última la vecindad se adquiere ex lege. Decía DE CASTRO que con esta regulación (que con ligeras modificaciones ya figuraba así en el art. 15 de la segunda edición del Código civil) se llegó a una solución de compromiso entre los dos sistemas que dividían a la legislación y doctrina anterior, pues por una parte se respetó el sistema de plazos automáticos ${ }^{38}$, y por otra la voluntad individual. De hecho, el autor estimaba que la balanza quedaba así inclinada a favor de la voluntad, aunque en un caso sea de, a su juicio, voluntad tácita (facta concludentia). Como este será uno de los puntos más debatidos en la Proposición de Ley, por las diferentes visiones de lo que es voluntad de una persona, dejamos para más adelante su comentario.

\subsection{Conservación de la vecindad civil}

Derivado del art. 14.5 CC nos encontramos con que, si antes del transcurso de los diez años de residencia en determinado territorio, se efectúa una declaración manifestando la voluntad de querer conservar la vecindad civil ya ostentada, no operará la adquisición automática de la vecindad del territorio en el que se tenga el domicilio. Como señala Álvarez González con apoyo en la RDGRN n02/2009 de 26 de enero ${ }^{39}$, el

\footnotetext{
37 Vid. nota 30.

38 Le Ley municipal de 1870 preveía una adquisición ipso facto de la vecindad por el transcurso de diez años, sin posibilidad de manifestación en contrario. Recogido por DE CASTRO y BRAVo, Derecho civil... op.cit., p. 476.

39 JUR 2010/99178.
} 
momento relevante para tomar en consideración la declaración será el de su presentación ante el Registro Civil competente, y no el de la formalización del acta de la declaración ${ }^{40}$.

\subsection{Recuperación de la vecindad civil perdida}

Aunque a veces se ha querido ver como recuperación de la vecindad civil perdida los supuestos de residencia en los que es una antigua vecindad la que se recupera (por ejemplo, que un gallego de origen haya residido diez años en León, y por tanto adquirido la vecindad civil común, pero después vuelva a Galicia y al cabo de dos años manifieste su intención de volver a tener la vecindad gallega), lo cierto es que no son supuestos de recuperación propiamente dichos, sino de adquisición sujeta a las reglas generales ${ }^{41}$. En el mismo sentido, tampoco lo serían los supuestos en los que se optase por una vecindad civil que ya se hubiese ostentado con anterioridad. El único caso previsto actualmente de recuperación sería aquel ligado a la recuperación de la nacionalidad española (art. 15.3 CC), obteniéndose la vecindad civil que ostentase el sujeto en el momento de su pérdida ${ }^{42}$.

Por lo tanto, la recuperación de la vecindad civil perdida como tal no está contemplada en la actual regulación del CC, y será otra de las reivindicaciones de la Proposición de Ley que a continuación pasamos a abordar.

\section{LA PROPOSICIÓN DE LEY POR LA QUE SE MODIFICA EL CÓDIGO CIVIL EN RELACIÓN CON EL ESTATUTO PERSONAL Y LA VECINDAD CIVIL}

Que se quiera modificar el régimen de la vecindad civil no es algo que haya surgido espontáneamente de las Cortes de Aragón. Todo parece remontarse al Congreso Nacional de Derecho civil celebrado en Zaragoza entre el 3 y el 9 de octubre de 1946, en el que se contemplaron los problemas planteados por «unos regímenes forales que tienen plena vigencia y arraigo innegables y cuentan con el afecto de los naturales del territorio en que rigen» ${ }^{43}$. Este «arraigo innegable» ya había quedado constatado en 1889, con la segunda edición del Código civil, cuando se pasó de un sistema unilateral y sin reciprocidad a otro recíproco, en una de las cuestiones más controvertidas de esta institución: que se adquiera automáticamente la vecindad civil del lugar en el que se reside transcurridos diez años sin declaración en contrario. Si en la primera edición del Código civil la idea era extinguir los derechos forales por el

\footnotetext{
${ }^{40}$ S. Álvarez GonzÁlez, "Domicilio, vecindad...", op.cit., p. 358.

41 J. Delgado Echeverría, "Comentarios a los artículos...", op.cit., p. 418.

42 En cambio, como bien advierte J. Delgado EcheverRía, "Comentarios a los artículos...", op.cit., p. 419, los extranjeros que obtengan la nacionalidad española podrán optar entre la vecindad de su residencia, de su lugar de nacimiento, la última de sus progenitores o adoptantes, o la de su cónyuge. Por tanto, se da la paradoja de que los extranjeros, al obtener la nacionalidad española, «tienen mayor libertad para determinar su vecindad que los nacionales de toda la vida».

43 J. L. LACRuz Berdejo, "El Congreso Nacional de Derecho Civil de 1946", Anuario de Derecho Civil, núm. 1, 1948, p. 147.
} 
procedimiento de que cada vez tuviesen menos sujetos afectados por él ${ }^{44}$, la segunda edición rectifica, y el transcurso de diez años en cualquier territorio determinará la adquisición de la vecindad que sea, ya sea común o foral ${ }^{45}$.

Del Congreso de Zaragoza de 1946 también cabe destacar otras dos relevantes conclusiones que trataron cuestiones que, como veremos, reaparecieron en el debate parlamentario de la Proposición de Ley. La primera de ellas afirmaba la necesidad de una «ley reguladora de las relaciones interregionales», petición que sigue vigente en la actualidad, siendo bastantes los autores que siguen reclamando una ley de derecho interregional privado, como tendremos ocasión de exponer más adelante. Por otra parte, la segunda conclusión definitiva propugnaba, entre otras cosas: que la vecindad civil debía ser fácil y sencillamente conocida y consignada en todos los actos del Registro Civil y en los documentos de identidad; que en ningún caso se adquiriría por la simple residencia o vecindad administrativa y sin declaración expresa del sujeto, la cual debía de ser inscrita en el Registro Civil y anotada en las actas de nacimiento y matrimonio; y que quienes la hubiesen perdido por la simple residencia administrativa, podrían recuperarla en el plazo de un año desde publicada la ley ${ }^{46}$.

En 1974 se modificó el Título Preliminar del Código Civil, lo que también afectó a la materia aquí tratada. Pero los cambios no fueron muchos, limitándose la reforma de la regulación de la vecindad civil a recoger la definición que la doctrina había ido elaborando sobre lo que significaba este concepto (lo que, como vimos, quedó establecido en el apartado primero del art. 14), así como a añadir algún supuesto que hasta entonces no se había recogido legalmente ${ }^{47}$.

\footnotetext{
44 ALONSO MARTínez, gran impulsor de la codificación civil en España, entendía que se debía publicar un Código civil que desterrase la anarquía legislativa en que vivían para aproximarse a la uniformidad de la legislación en todo el reino. Y aun conservándose en las provincias aforadas aquellas instituciones que, por estar muy arraigadas, fuesen imposibles de suprimir, estas subsistirían tan solo como excepción de una regla común, y acercándose todo cuando pudiesen a la unidad legislativa. M. Alonso MARTínEZ, El Código civil en sus relaciones con las legislaciones forales, Madrid, Est. Tipográfico de P. Núñez, 1884. Así y todo, de este autor se ha dicho que destacó sobre todo por su labor de búsqueda de compromiso con los territorios forales, preocupación que se observa a lo largo de toda la obra. M. P. GARCÍA RuBio / F. MÉndez GarCíA, Douscentos anos do Code civil des Francais na USC (1804-2004), Universidad de Santiago de Compostela, 2005, p. 123.

${ }^{45}$ Para un análisis detallado de la primitiva redacción del art. 15 CC, vid. M. LIRIA LAFARGA, "La Regionalidad o Vecindad civil", Jornadas de Derecho Foral, Jaca 27-31 agosto, 1972, pp. 13-19, quien recoge las principales críticas que recibió de la doctrina, lo que desembocó en su reformulación en la segunda edición del Código. Exponerlas aquí excedería el propósito de este trabajo, por lo que como bien dice el autor al final de su análisis, p. 19, «el resumen de la crítica a que da pie el primitivo art. 15, es que este estaba muy lejos de aceptar el principio de absoluta equiparación entre los diversos ordenamientos, principio que hoy inspira toda la regulación de la vecindad civil».

${ }^{46}$ Recogidas por J. Delgado ECHEVERRÍA, "Vecindad civil y derecho...", op.cit., p. 4.

47 Sobre la reforma, vid. R. Bercovitz Rodríguez-CANo, "Arts. 14 y 15", Comentarios a las Reformas del Código Civil. El nuevo Título Preliminar del Código y la Ley de 2 de mayo de 1975, Tecnos, Madrid, 1977, pp. 703-729.
} 
Otro antecedente que tampoco debemos ignorar es el Proyecto de Reforma del Título Preliminar del Código civil de 1983 y publicado en 1985, elaborado por la sección primera de la Comisión General de Codificación. En él se contenían algunas de las peticiones del Congreso de 1946 y se modificaba algún aspecto a mayores. Pero este Proyecto tampoco llegó nunca a buen puerto.

Los extremos plasmados en las conclusiones del Congreso de 1946 y en parte del Proyecto de 1983 son similares a lo que ahora se solicita en la Propuesta de las Cortes de Aragón. En ella se modifica el art. 14 del Código civil en dos aspectos, y se añade una disposición transitoria sobre recuperación de la vecindad civil $^{48}$. Analizaremos a continuación su contenido.

\subsection{Ampliación de la facultad de opción del hijo}

En primer lugar, la Propuesta de Ley modificaría el párrafo cuarto del art. 14.3 CC, que quedaría redactado como sigue:

«En todo caso, el hijo, desde que cumpla catorce años y hasta que transcurran cinco años desde su emancipación, podrá optar bien por la vecindad civil del lugar de su nacimiento, bien por la vecindad que hubieran tenido cualquiera de sus padres. Si no estuviera emancipado, habrá de ser asistido en la opción por el representante legal».

De esta manera se están dando mayores posibilidades a la libertad de decisión, ampliando el plazo de un año del que actualmente dispone el hijo, a cinco años, y además podrá optar no solo por la última vecindad de cualquiera de los progenitores, sino por cualquier vecindad que hubiesen tenido, independientemente de la residencia. Así, la edad máxima que tendrá el hijo se situará entre los veintiún y los veintitrés años, dependiendo de si hubo una emancipación strictu sensu o de si alcanzó la mayoría de edad a los dieciocho años.

La justificación que la Exposición de Motivos de la Ley da a esta modificación en la es la debida trascendencia que se quiere dar al ius sanguinis frente a la preponderancia del ius soli, diciéndose literalmente que «los hijos deben poder conservar la opción de reivindicar su origen foral, independientemente de que sus padres se hayan visto obligados, por necesidades familiares, a trasladarse a otra comunidad foral o a territorios sujetos a derecho común».

Los expertos que fueron llamados a comparecer en el Congreso de los Diputados expresaron, en su gran mayoría, su acuerdo con la ampliación del plazo de uno a cinco años. Formularon una comparativa con las

\footnotetext{
48 Sobre la Proposición de Ley de 2018 solo nos consta que se haya tratado por J. Delgado ECHEVERRÍA, "Vecindad civil y derecho...", op.cit. También cita brevemente la Proposición A. LóPEZ AzCONA, "La política legislativa de la Comunidad autónoma de Aragón en materia de Derecho civil propio: de la Compilación de 1967 al Código del Derecho foral de Aragón de 2011 e iniciativas legislativas ulteriores", Iura Vasconiae, $13 / 2016$, p. 390 , diciendo que considera muy razonable la previsión relativa a la adquisición y correlativa pérdida automática de la vecindad civil por residencia continuada durante diez años, pero no se pronuncia sobre los otros dos extremos de la Proposición de Ley.
} 
reformas que han ido ampliando la posibilidad que se concede a los hijos de optar por la nacionalidad española, y aunque el plazo de opción es diferente, se valora como indudable mejora desde los parámetros del ejercicio subjetivo por parte del hijo mayor de catorce años.

Sobre la posibilidad de que puedan optar por cualquiera de las vecindades civiles que hayan tenido los progenitores, algunos diputados se mostraron escépticos, criticando la fórmula por ser demasiado abierta (sobre todo cuando los progenitores hayan tenido varias vecindades), o que podía generar cierta inseguridad. Tampoco entendían algunos que los hijos pudiesen elegir una vecindad civil con la que no tuviesen prácticamente vinculación ${ }^{49}$. No obstante, según la opinión de uno de los comparecientes, esta previsión tiene más valor simbólico que otra cosa, ya que en muy raros casos, al igual que sucede con la opción de los padres de decidir durante los seis meses siguientes al nacimiento qué vecindad civil le atribuyen al hijo, se irá al Registro Civil a hacer valer tal derecho de opción ${ }^{50}$.

\subsection{Supresión de la adquisición por residencia continuada de diez años}

En segundo lugar, la Proposición de Ley modifica el art. 14.5 CC, en el que se suprime la adquisición de la vecindad civil por residencia continuada de diez años, sin declaración en contrario durante ese plazo. Por tanto, el art. 14.5 CC quedaría redactado como sigue:

«La vecindad civil se adquiere por residencia continuada durante dos años, siempre que el interesado manifieste ser esa su voluntad. La declaración se hará constar en el Registro Civil y no necesita ser reiterada».

Como vemos, se siguen manteniendo los dos años necesarios de residencia para poder optar por nueva vecindad. La residencia debe ser habitual, como propugna el art. 225 del Reglamento de Registro Civil, por lo que no cabría inscribir aquellas declaraciones en las que se asegure vivir en un sitio pero realmente se resida en otro. De darse estos supuestos, más que fraudulentos serían de simulación en la adquisición de la vecindad $\mathrm{civil}^{51}$. Y es que si se cumplen los requisitos para que se dé un cambio de vecindad, se deben obviar los motivos por los que una persona pretende ese cambio, aunque con ello se aplique una ley más favorable a sus intereses, lo que es especialmente notable en el ámbito sucesorio ${ }^{52}$.

49 De este tenor fue la opinión de M. E. Ginebra Molins, en su comparecencia ante el Congreso. Diario de sesiones del Congreso de los Diputados, Comisión de Justicia, 9 de marzo de 2017, p. 4.

50 J. Delgado ECheVerRía, en su comparecencia ante el Congreso. Diario de sesiones del Congreso de los Diputados, 22 de febrero de 2017, p. 13.

51 A. FONT y SEgURA, Actualización y desarrollo del sistema de Derecho interregional, Universidade de Santiago de Compostela, 2007, p. 148; M. E. ZaBALO ESCUDERO, "Autonomía de la voluntad...", op.cit., p. 406; S. Álvarez GonzÁlez, "Domicilio, vecindad...", op.cit., p. 358; J. Delgado ECheVERRÍA, "Vecindad civil y derecho...", op.cit., p. 12.

52 En la SAP de Teruel 28/2015 de 1 de julio (JUR 2015\194630) se alega por el apelante que el testador había adquirido la vecindad civil aragonesa con la única intención de 
Ello viene justificado por la coexistencia en régimen de igualdad de los distintos Derechos civiles, y por la libertad que permiten los arts. 14 y 15 del CC a la hora de optar por una vecindad civil o adquirirla por declaración expresa tras dos años de residencia en determinado lugar. Así se desprende de la STS de 14 de septiembre de 2009, en la que se dice que «no puede utilizarse un argumento relacionado con la problemática de la mayor o menor legitimidad de los derechos autonómicos para considerar que existe fraude cuando se utiliza una ley que permite los cambios de vecindad para alterar el punto de conexión y así permitir la aplicación de otra ley más favorable a los intereses del declarante» ${ }^{53}$.

Como decíamos, sí que podrá haber casos de simulación en la adquisición de vecindad civil, y aquí es en donde entra en juego la cuestión de la prueba, pues en la práctica no serán pocos los casos en los que resulte complicado determinar la vecindad civil que ostenta una persona. Tanto la doctrina ${ }^{54}$ como los tribunales ${ }^{55}$ y la Dirección General de Registros y del

testar según la Ley 1/1999, de 24 de febrero, de Sucesiones por causa de muerte de Aragón, vigente en el tiempo en que se realizó el testamento, a lo que el Tribunal responde que nada puede llevar a pensar eso, pues el testador llevaba más de treinta años residiendo en territorio aragonés (FJ $2^{\circ}$ ). En la otra cara de la moneda, S. ÁlvAREZ GoNZÁLEZ, "Domicilio, vecindad...", op.cit., pp. 358-359 cita varias sentencias en las que sí se aprecia una simulación en la adquisición de la vecindad civil (entre otras, STS 5 abril 1994, RJ 1994\2933; SAP Barcelona 4 noviembre 2003, RJ 2009\4445; SAP Madrid 27 abril 2007, AC 2007\1047). Por último, muy ilustrativa es la SAP de La Rioja 107/2014 de 7 de abril (JUR 2014\136047), en la que se aprecia una simulación («fraude de ley» según el Tribunal) en la adquisición de la vecindad civil de un matrimonio, y en la que se concluye que el matrimonio desarrolló su vida personal y patrimonial en La Rioja, «sin que llegaran a residir en Mendavia de forma estable y continua, en la forma precisa para adquirir la vecindad civil navarra, que no fue sino una ficción, articulada a través del empadronamiento en Mendavia, la compra de una vivienda en dicha localidad, y el cambio de domicilio fiscal, así como de la indicación en todo tipo de documentos públicos y privados como domicilio Mendavia, sin corresponder a su residencia efectiva, y todo ello para apartar a sus hijas de sus derechos hereditarios» (FJ $\left.4^{\circ}\right)$.

53 F.J. 70 de la STS 588/2009, de 14 de septiembre (RJ 2209/4445). Así y todo, el Tribunal Supremo había declarado la existencia de fraude en la obtención de la ley vizcaína, en su Sentencia de 5 de abril de 1994 (RJ 1994/2933), lo que la doctrina puso en duda. En este sentido, vid. la doctrina citada por A. FONT y SEGURA, Actualización y desarrollo... op.cit., p. 144, nota a pie 303.

54 Sobre la dificultad probatoria de la vecindad civil, vid. I. RiBAS Algueró, La Vecindad civil: problemática en torno a su régimen jurídico y a su prueba, Bosch, Barcelona, 1984, especialmente pp. 253-275. La autora afirmaba que «a pesar de la importancia que tanto la doctrina científica como las resoluciones judiciales han prestado al tema de la prueba de la vecindad civil, no existe un sistema normativo adecuado que realmente proporcione la certeza de la vecindad civil que ostenta una persona», palabras que hoy, más de tres décadas después, siguen plenamente vigentes.

${ }^{55}$ Como recoge R. Bercóvitz RODRíGUez-CANo, "Artículos 13,14 y 15", op.cit., p. 112, los Tribunales suelen presumir como vecindad civil la del domicilio, en especial cuando este se encuentra en territorio de su competencia; o la del lugar de nacimiento cuando coincide con la vecindad que se pretende y con la residencia habitual. En cambio, el padrón municipal, el domicilio tributario, los destinos de los funcionarios, la ostentación de cargos públicos o representativos y las certificaciones de entes administrativos no son prueba suficiente, normalmente, si no van acompañados con la existencia de residencia habitual. 
Notariado ${ }^{56}$ coinciden en la dificultad de probar la vecindad civil. Y es que, como bien señala PARRA Lucán, ni siquiera en los casos en los que conste una declaración de voluntad al respecto en el Registro Civil se puede estar seguros de que corresponde a la vecindad civil actual, y ello porque el sistema vigente permite los cambios de vecindad sin contar con la voluntad del interesado ${ }^{57}$. En cambio, de aprobarse la Proposición de Ley comentada, esta cuestión quedaría resuelta, pues desaparecería la adquisición automática por el transcurso de diez años. No obstante, el asunto sobre la prueba seguirá teniendo su enjundia, como pasamos a exponer a continuación.

Está claro que cuando la vecindad conste en el Registro Civil -recordemos que es un hecho inscribible, según el todavía vigente art. 1. 70 de la Ley de Registro Civil de 1957 (LRC 1957) y que lo seguirá siendo cuando entre en vigor la Ley de Registro Civil de $2011^{58}$ (LRC 2011), pues la misma previsión consta en su art. 4.50- no habrá más duda que la expuesta previamente, es decir, que no sepamos si se ha adquirido nueva vecindad por el transcurso de al menos diez años residiendo en otro territorio.

Cuestión diferente será cuando no conste en el Registro Civil. Aquí entrará en juego el vigente art. 96.20 LRC 1957 -que se mantiene en el art. 92.1.b) LRC 2011- que establece que puede declararse con valor de simple presunción la vecindad cuando no conste en el Registro Civil. Actualmente se prevé que esta declaración se haga mediante expediente gubernativo, pero en la práctica no se recurre a dicho expediente ${ }^{59}$, y de hecho en el nuevo art. 92 LRC 2011 ya no se menciona, recogiéndose que será por medio de un previo procedimiento registral por el que se declaren las presunciones que enumera. Además, el mismo artículo se remite, en su apartado segundo, al futuro reglamento, que será el que determine

${ }^{56}$ I. RibAs Algueró, La vecindad civil... op.cit., pp. 254-255, citando la Resolución de 3 de julio de 1967: «...las dificultades para su prueba son, como puso de relieve la Resolución de 23 de junio de 1964, de las más arduas que puedan plantearse, ya que, en términos generales, no hay datos suficientes para estimar positivamente o basar en la inscripción del Registro Civil estas circunstancias». También se aprecia esta dificultad probatoria en las resoluciones de 6 de noviembre de 1980, 8 de marzo de 2012 y, más recientemente, en el FD $3^{\circ}$ de la Resolución de 11 de mayo de 2017 (recurso interpuesto contra la negativa de la registradora de la propiedad de Lleida n. 01 a inscribir el convenio regulador de un decreto de divorcio, BOE de 29 de mayo de 2017), cuando se dice que al no existir constancia en el Registro civil que avale la vecindad civil catalana propugnada por el recurrente, la DGRN aplica la regla que podríamos denominar «de la incertidumbre»: que en caso de duda, la vecindad civil será la del lugar de nacimiento (art. 14.5 CC en su redacción al tiempo de la celebración del matrimonio, art. 14.6 CC actual).

57 M. A. PARRA LUCÁN, "Comentarios a los artículos...", op.cit., p. 182.

58 Todavía en vacatio legis, conforme a su disposición final $10^{a}$, entrará en vigor el 30 de junio de 2020, excepto las disposiciones adicionales séptima y octava y las disposiciones finales tercera y sexta, que entraron en vigor el 23 julio 2011, los artículos 49.2 y 53 que entró en vigor el 30 junio 2017 y los arts. 44 a 47, los apartados 1 y 4 del art. 49, los arts. 64 y 66, el apartado 3 del art. 67 y la disposición adicional novena, que entró en vigor el 15 octubre 2015. La última reforma de esta disposición final $10^{a}$ fue realizada por la Ley 5/2018, de 11 de junio, de modificación de la Ley $1 / 2000$, de 7 de enero, de Enjuiciamiento Civil, en relación a la ocupación ilegal de viviendas.

59 M. A. PARRA LUCÁN, "Comentarios a los artículos...", op.cit., p. 182. 
cómo acreditar estas circunstancias, por lo que la doctrina aún no se atreve a aventurar qué camino seguirá esta actividad probatoria que garantice la obtención de la declaración con valor de simple presunción ${ }^{60}$. Sobre la posible función del Notario como profesional con potestad para acreditar estas circunstancias, si bien en un primer momento se admitió la prueba de la vecindad civil mediante acta de notoriedad ${ }^{61}$, tras las RRDGRN de 21 de noviembre 1992 y 13 mayo 1996 parece clara la exclusión de toda virtualidad a la escritura notarial que recoja la voluntad de conservar determinada vecindad ${ }^{62}$.

Por otro lado, también podrá presumirse la vecindad civil por el lugar de nacimiento. Este extremo sí que cambió con la nueva LRC 2011, pues aunque la presunción ya consta en el actual art. 68 LRC 1957 - art. 69 LRC 2011- y aunque se sigue contemplando el lugar de nacimiento como dato que debe figurar en la inscripción de nacimiento -arts. 44 y 49 LRC 2011 , que ya entraron en vigor en virtud de la Ley $19 / 2015^{63}$, en cambio ya no se contiene la previsión del art. 16.2 LRC 1957, que permitía que los progenitores pudieran inscribir como lugar de nacimiento no solo aquel en el que haya acaecido, sino también el del Registro Civil Municipal correspondiente al domicilio del progenitor o progenitores legalmente conocidos. Si esto lo ponemos en relación con el art. 46 LRC 2011, que prevé que sean los centros sanitarios quienes remitan la comunicación de Ios nacimientos a la Oficina del Registro Civil que corresponda, se plantea la duda de si los progenitores podrán especificar en el documento que se remita -y cuyos extremos todavía no han sido desarrollados, pues la cuestión se deja a un futuro reglamento- un municipio diferente al del centro hospitalario. Si bien la previsión del art. 16.2 LRC 1957 ha desaparecido, lo cierto es que tampoco se les prohíbe que especifiquen el municipio de procedencia. $Y$ es que en muchos casos el nacimiento ocurrirá en un municipio de mayor población que el de origen, en el que seguramente no haya un centro hospitalario. Con la actual situación de despoblación de núcleos rurales la cuestión no es menor, por lo que no sería insensato que se plantease la consulta a la DGRN, con el objeto de permitir que en las inscripciones siguiese constando el concreto municipio de procedencia de los progenitores.

Sobre la declaración ante el encargado del Registro Civil de querer conservar o adquirir determinada vecindad, la doctrina se ha preguntado sobre la aparente falta de garantías del Registro Civil en relación con la

60 P. Cremades García, "Artículos 92 y 93", Comentarios a la Ley de Registro Civil, J.A. СoвACHo Gómez / A. LeCiÑEnA IBARRA (Dirs.), Thomson Reuters-Aranzadi, Navarra, 2012, p. 1268.

61 M. A. PARRA LUCÁN, "Comentarios a los artículos...", op.cit., p. 182, citando la RDGRN 3 de julio 1967, 6 de noviembre 1980 (RJ 1980/4312).

62 En este sentido, J. Delgado ECheVerRía, "Comentarios a los artículos...", op.cit., p. 411, quien se apoya en las resoluciones citadas, en el art. 64 LRC 1957 y en los arts. 229 y 230 del Reglamento de Registro Civil para decir que la declaración de voluntad hoy en día debe seguir haciéndose ante el encargado del Registro Civil.

63 Ley $13 / 2015$, de 13 de julio, de medidas de reforma administrativa en el ámbito de la Administración de Justicia y del Registro Civil. Los artículos 44 y 49 entraron en vigor el 15 de octubre de 2015. 
aplicación del principio de legalidad a dichas declaraciones. Se cuestiona si basta o no con el empadronamiento, y si existe alguna actuación encaminada a comprobar la veracidad de la declaración en lo relativo a la residencia habitual del declarante ${ }^{64}$. En principio, la jurisprudencia del Tribunal Supremo ha venido rechazando que la inscripción en el padrón municipal sea un dato que pruebe la vecindad civil, y tampoco admite la presunción de vecindad civil del lugar de residencia, si bien reconoce la relevancia de este último cuando se sigue manteniendo en el lugar en que se inscribe ${ }^{65}$.

En cuanto a la eficacia de las inscripciones relativas a las declaraciones de voluntad sobre la vecindad civil, con la LRC 2011 estas pasarán a tener naturaleza constitutiva ${ }^{66}$, como se afirma en el art. 68.1, por lo que se cambia radicalmente la situación con respecto a lo previsto actualmente en el art. 64 de la LRC 1957, pues si se conjuga este con el art. 14.5 CC se deduce que la inscripción es meramente declarativa ${ }^{67}$.

Volviendo al tema objeto de análisis en este apartado, el ya citado Proyecto de Reforma del Título Preliminar del Código civil de 1983 también suprimía esta forma de adquisición automática de la vecindad civil por residencia continuada de diez años ${ }^{68}$, pues en la doctrina se criticaba bastante por operar al margen de la voluntad del interesado ${ }^{69}$. Al respecto, entendemos que de forma un poco contradictoria, el Proyecto de 1983, a la vez que suprimía esta regla, disminuía el tiempo necesario para optar por la nueva vecindad: solo serían necesarios seis meses de residencia habitual. La doctrina lo justificó, por un lado, en que de esta manera se permitiría una mejor integración en los territorios de inmigración, y por otra, en que se iría produciendo un acercamiento entre la vecindad civil y la condición política, tendiéndose a eliminar la existencia de una disociación entre ambos conceptos ${ }^{70}$.

Por su parte, la Exposición de Motivos de la Proposición de Ley de 2018 justifica dicha supresión en que parece excesivo que se pierda sin declaración ninguna del interesado, y sin hacer ninguna averiguación sobre si se quiere o no cambiar su estatuto personal. La idea de indagar la

64 R. Bercovitz Rodríguez-Cano "Comentario a la Sentencia de 14 de septiembre de 2009: Vecindad civil; fraude de ley", Cuadernos Civitas de jurisprudencia civil, núm. 83, 2010 , p. 1122.

65 M. A. PARRA LUCÁn, "Comentarios a los artículos...", op.cit., p. 183, citando, entre otras, las SSTS de 20 de febrero de 1995 (RJ 1995/2771) y 4 de julio de 1995 (RJ 1995/5462).

${ }^{66}$ Es decir, que la inscripción es imprescindible para que surta efecto.

${ }^{67}$ Así lo entiende J. Delgado ECheVerRía, "Comentarios a los artículos...", op.cit., p. 411.

68 También fue de este tenor la conclusión $5^{a}$ del Congreso de Jurisconsultos sobre Derechos civiles territoriales en la Constitución, celebrado en 1981 en Zaragoza, que propugnó el principio de voluntariedad en la adquisición de una vecindad distinta a la originaria. M. A. PARRA LUCÁN, "Comentarios a los artículos...", op.cit., p. 178.

69 Entre otros, J. Bermejo Vera / J. Delgado EcheVerría, "Artículo 9", Comentarios al Estatuto de Autonomía de la Comunidad Autónoma de Aragón, J. Bermejo VerA (Dir.), Instituto de Estudios de Administración local, Madrid, 1985, p. 86, quienes muy gráficamente se refieren así a la ausencia de voluntad en la pérdida de vecindad civil ex lege: «Aunque no se sepa. Aunque, de saberlo, no se hubiera querido».

70 M. A. PARRA LUCÁN, "La vecindad civil: en torno a un proyecto de reforma", Revista Jurídica de Navarra, núm. 5, Navarra, 1988, p. 72. 
intención, el «ánimo» del sujeto, no es nueva. Como nos recuerda DE CASTRO, la jurisprudencia del Tribunal Supremo fue reflejando durante la segunda mitad del S. XIX y hasta unos años después de promulgado el Código civil las inseguridades de la doctrina sobre este tema. Así, en la STS de 27 de noviembre de 1868, se decía que para el cambio de vecindad no era suficiente con la «ausencia temporal» ni «la simple residencia en punto diferente», considerándose necesario «el establecimiento del individuo en el pueblo a que se traslade con ánimo de permanecer en él» ${ }^{71}$. En otras sentencias se precisó de la búsqueda de la "verdadera voluntad", como sucedió en las STS de 29 de marzo de 1892, en la que el plazo de los diez años de residencia continuada se consideró de presunción de voluntad, pero subordinada a la prueba en contrario, lo que sucedía en el caso, al probarse que el interesado se encontraba en «constante propósito de volver a Castilla y, por tanto, de conservar su estatuto de origen ${ }^{72}$. Finalmente, un tercer grupo de sentencias presumían la voluntad de ciertos hechos, convirtiéndose estos en requisito único de prueba de la vecindad y por tanto en presunción iuris et de iure. Dentro de estas últimas se encontraban, por ejemplo, las SSTS de 7 de febrero de 1899, en la que fue decisivo que el interesado residiese en el pueblo con casa abierta por más de un año, o la de 30 de octubre de 1901, que siguiendo «los preceptos legislativos comunes y forales anteriores y posteriores», declaró como único requisito el transcurso de diez años o la residencia de dos con voluntad manifiesta ${ }^{73}$. De hecho, durante la redacción del Código, la doctrina dudó sobre si debía mantenerse el valor preponderante dado a la voluntad o bien debía señalarse un plazo fijo de residencia para el cambio de los estatutos ${ }^{74}$.

Durante el debate parlamentario de la Proposición de Ley que aquí nos ocupa hubo argumentos tanto a favor como en contra de la modificación, y que atendiendo a ese valor simbólico que podríamos atribuir a la vecindad civil, se traduciría en que en los primeros se estaría dando un mayor peso a la idea del origen, mientras que en los segundos a la del arraigo: de desaparecer la adquisición automática de la vecindad civil, se

\footnotetext{
${ }^{71}$ DE CASTRO (1952), pp. 469 y 476, nota a pie 2, diciendo que «la jurisprudencia anterior al CC atendió preferentemente a la voluntad de ganar vecindad, y lo mismo hará la posterior, cuando se trata de casos en que ha de aplicarse la antigua legislación. Por explicable conservadurismo, algunas sentencias que aplican el art. 15 utilizan parecidos términos. Así, la STS de 20 de abril de 1917 entiende decisivo "el propósito de adquirir otra vecindad"». La doctrina (citada por DE CASTRO) tampoco se ponía de acuerdo sobre el tema del animus: mientras que algunos entendían que la vecindad se adquiría involuntariemante por la sola residencia de diez años (COLL Y RODÉs, también TRÍAS), otros decían que era necesario que interviniese el ánimus, exigiendo una residencia definida o con intención de que lo sea.

72 F. De CASTRO Y BRAVO, Derecho civil... op.cit., p. 469, nota a pie 5. El autor también cita otras sentencias que tratan de la búsqueda de la «verdadera voluntad», como las STS de 23 de diciembre de 1904 (en la que se daban manifestaciones ostensibles de querer ganar vecindad) o la de 11 de febrero de 1902, en donde se patentiza la voluntad del interesado por modo claro y expreso.

${ }^{73}$ F. DE CASTRO Y BRAVO, Derecho civil... op.cit., p. 469, nota a pie 6.

${ }^{74}$ F. De Castro y BRAvo, Derecho civil... op.cit., p. 470, citando a doctrina de la época.
} 
estaría manteniendo aquella adquirida originariamente, que en la mayoría de los casos será la transmitida por los progenitores (ius sanguinis), y de mantenerse la regulación como está, se seguiría fomentando la adquisición automática de aquella en donde se resida (ius soli).

\subsubsection{Argumentos a favor de la modificación del CC}

Desde el punto de vista técnico, las justificaciones que se dieron en apoyo a la reforma y en la línea con la idea de prevalencia del origen apelaron básicamente a dos instituciones: la autonomía de la voluntad y la seguridad jurídica.

Sobre la primera, el debate se centró en cómo se puede conocer mejor la voluntad del sujeto. Y los defensores de la reforma lo tenían claro: con una declaración libre y espontánea de quien la formula, y no de una presunción de voluntad de adquirir automáticamente la vecindad del lugar en el que se reside diez años ${ }^{75}$. De hecho, lo normal será que los hechos sobre los que se fundó una pérdida o adquisición de vecindad civil tengan lugar mucho antes de que haya una controversia motivada precisamente por esa adquisición o pérdida. Esos momentos controvertidos serán, básicamente, dos: el del divorcio, debido a los diferentes regímenes económico-matrimoniales que puedan prever las distintas normas civiles; y el del fallecimiento, en el que, además de otras figuras propias de cada régimen foral, por su configuración tan diversa en unos y otros, ocupará un lugar protagonista la legítima ${ }^{76}$. En palabras de DeLGADO ECHEVERRÍA, daría mucha más seguridad jurídica que solo por voluntad expresa se pudiese cambiar de vecindad civil, pues se acabaría con problemas de pérdidas de vecindad civil indeseadas, o de indagaciones de estas posibles pérdidas por parte de herederos a los que les conviene más un régimen previsto en otro Derecho civil, o de cónyuges que se divorcian y les conviene más un determinado régimen económico-matrimonial previsto en alguno de los derechos civiles especiales y no en otro ${ }^{77}$.

En segundo lugar, los comparecientes favorables a la reforma justificaron que la supresión del sistema de pérdida automática de la vecindad civil acabaría con gran parte de la conflictividad generada en esta materia en

\footnotetext{
75 En este sentido, M. A. Egusquiza Balmaseda, J. Delgado Echeverría y L. L. Montes Bel, en sus comparecencias ante el Congreso. Diario de sesiones del Congreso de los Diputados, Comisión de Justicia, 22 de febrero de 2017. En palabras de L. L. MONTES BEL, pp. 20-21, «desde la perspectiva del estatuto civil de la persona, no puede entenderse que quien calla otorga, sino que quien calla no dice nada».

76 Sobre este extremo, vid. el trabajo de Álvarez González, S., "Legítimas y Derecho interregional", Tratado de legítimas, TORRES GARCÍA, T. (Coord.), Atelier, 2012, pp. 153202, en el que partiendo del art. 9.8 CC, norma clave de determinación de la ley aplicable en materia sucesoria, expone la problemática en torno al papel que desempeñan las legítimas en el Derecho interregional, especialmente cuando el causante no tenía la misma vecindad civil en el momento de otorgar testamento y en el del fallecimiento (caso en el que entrarán en juego dos leyes sucesorias que muy probablemente discreparán en lo pretendido por el causante y lo permitido por una y otra ley).

77 J. Delgado EcheVerRía en su comparecencia ante el congreso. Diario de sesiones del Congreso de los Diputados, Comisión de Justicia, 22 de febrero de 2017, p. 9.
} 
los tribunales, lo que daría mayor seguridad jurídica al sistema (en especial al limitarse el ámbito de aplicación de la presunción sobre vecindad civil que se recoge en el art. 69.2 de la Ley del Registro Civil (LRC) y el valor de la declaración, simplemente presuntivo que cabe inscribir conforme al art. 92.1 b) LRC) ${ }^{78}$. Ejemplo reciente de esta conflictividad es la SAP de Barcelona $495 / 2018^{79}$, en la que la dificultad probatoria fue determinar si el causante ostentaba vecindad civil aragonesa o catalana, ya que aunque de origen era aragonés, igual que su mujer, habían vivido tiempo en Cataluña.

\subsubsection{Argumentos en contra de la modificación del CC}

En la postura contraria nos encontramos con expertos que creen conveniente dejar la redacción del art. 14.5 CC tal cual está ahora, afirmando que el régimen vigente tiene un alto grado de aceptación en la práctica, aunque no niegan los supuestos en los que alguien se da cuenta de que ha perdido su vecindad civil sin haberlo querido ${ }^{80}$. Sobre la autonomía de la voluntad dicen que esta se presume cuando la residencia se ha modificado, tesis que entienden que se ve apoyada por la STS de 16 de diciembre de $2015^{81}$, en la que se aclaró, por fin, si computaba o no dentro del tiempo de los diez años aquellos en los que el sujeto no estuvo en condiciones de oponerse (por motivo de edad o de incapacidad): al negar el tribunal que el plazo corriese, se está presumiendo que el sujeto sí tiene voluntad, y precisamente por eso se espera a empezar a computar el plazo una vez pueda oponerse ${ }^{82}$. Así y todo, en nuestra opinión, suponer que el sujeto tiene voluntad por el mero hecho de que no computa el plazo, nos parece que es mucho presumir.

Además, los defensores de esta postura argumentan que el verdadero problema no es una cuestión de voluntad tácita o expresa, sino más bien el desconocimiento generalizado en el hecho de contemplar la residencia como una circunstancia que pueda provocar un cambio de vecindad civil. Entienden que la previsión de que se adquiera de modo automático tiende a evitar que se perpetúen situaciones de extraterritorialidad, favoreciendo además la integración de la persona en

\footnotetext{
78 Según Egusquiza Balmaseda, M. A., las últimas sentencias dictadas en esta materia versan todas sobre adquisición de la vecindad civil por residencia continuada durante diez años, fuese voluntaria o no. Comparecencia ante el Congreso. Diario de sesiones del Congreso de los Diputados, Comisión de Justicia, 22 de febrero de 2017, p. 4.

79 SAP de Barcelona (secc. 18a), núm. 495/2018, de 5 de julio (JUR 2018\210468).

80 En este sentido, M. MARTÍNEZ MARTÍNEZ, en su comparecencia ante el Congreso. Diario de Sesiones del Congreso de los Diputados, BOE de 22 de febrero de 2017, p. 15.

${ }^{81}$ STS 704/2015, de 16 de diciembre (RJ 2015/6243).

82 R. DuRÁn RivaCoBA, en su comparecencia ante el Congreso. Diario de sesiones del Congreso de los Diputados, Comisión de Justicia, 22 de febrero de 2017, p. 25. También en R. DuRÁn Rivacoba, "Comentario a la sentencia del Tribunal Supremo de 16 de diciembre de 2015 (5808/2015). Cómputo del plazo en materia de adquisición de la vecindad civil", Comentarios a las sentencias de unificación de jurisprudencia, Vol. 7, Dykinson, 2015, pp. 731-745.
} 
el territorio y la sujeción a su derecho ${ }^{83}$, siendo la «clave del tema» la «relación con el territorio y con el pueblo que vive en el territorio» ${ }^{84}$. Incluso uno de los comparecientes calificó a la propuesta de ir «a contracorriente», justificándolo en que la tendencia general era que la ley aplicable y la ley del foro sean la misma, es decir, adoptar un criterio territorial ${ }^{85}$.

Por último, en cuanto al tema de la seguridad jurídica, dicen precisamente que lo que pretende el art. $14.5 \mathrm{CC}$ es dar mayor seguridad a quienes llevan más de diez años viviendo en un territorio ${ }^{86}$, y que el plazo es suficientemente largo como para denotar cierto arraigo y un alto grado de integración ${ }^{87}$.

A caballo entre la postura a favor y en contra de la reforma se encuentran algunas de las cuestiones planteadas por los diputados presentes durante la comparecencia de los expertos. Una de ellas versó sobre la posibilidad de implementar un sistema intermedio en el que se tuviese que demostrar cierto arraigo con ese territorio foral para recuperar esa vecindad civil, visto que la propuesta de las cortes de Aragón quiere ir hacia un sistema de mantenimiento de la vecindad civil, incluso en los casos en los que «se mantuviese por descuido» (por ejemplo, por haber nacido en Galicia pero trasladarse al año de edad a otro territorio, y no volver a Galicia). Y en similar línea, otro diputado se plantea si no habría demasiada discordancia entre la vecindad civil y la vecindad administrativa en aquellos casos en los que, conservando los progenitores una vecindad civil de un territorio en el que ya no viven, se la transmiten a los hijos, para los que aún sería más extraña esa vecindad civil.

Por último, plantean la cuestión de la irrevocabilidad, preguntando si el hecho de vivir otra vez en otro territorio durante mucho tiempo no daría algún derecho a que la persona que hizo esa declaración cambiase de idea y pudiese olvidarse de esa vecindad que eligió en un primer momento. No obstante, lo cierto es que siempre podrá adquirir nueva vecindad por el transcurso de dos años en ese territorio si así lo declara expresamente, o, en la redacción actual del código y si no se modifica con esta Proposición de ley, por el transcurso de diez años y sin declaración en contrario.

\subsection{Recuperación de la vecindad civil perdida}

La propuesta contiene una disposición transitoria que permitiría recuperar la vecindad civil perdida mediante una declaración en el Registro Civil.

${ }^{83}$ En este sentido, M. E. Ginebra Molins, en su comparecencia ante el Congreso. Diario de sesiones del Congreso de los Diputados, Comisión de Justicia, 9 de marzo de 2017, p. 4.

${ }^{84}$ En palabras de C. LASARTE Álvarez, en su comparecencia ante el Congreso. Diario de sesiones del Congreso de los Diputados, Comisión de Justicia, 9 de marzo de 2017, p. 16.

${ }^{85}$ R. Pratdesaba I Ricard, en su comparecencia ante el Congreso. Diario de sesiones del Congreso de los Diputados, Comisión de Justicia, 9 de marzo de 2017, p. 25.

${ }^{86}$ R. DuRÁn Rivacoba, en su comparecencia ante el Congreso. Diario de sesiones del Congreso de los Diputados, Comisión de Justicia, 22 de febrero de 2017, p. 25.

87 M. E. Ginebra Molins, en su comparecencia ante el Congreso. Diario de sesiones del Congreso de los Diputados, Comisión de Justicia, 9 de marzo de 2017, p. 4. 
Para ello se dispondría de un plazo de cinco años y no habría posibilidad de revocar esta declaración.

«Quienes hubieran perdido su vecindad civil a causa de la adquisición de otra por residencia continuada de diez años sin declaración en contrario, podrán recuperarla mediante la declaración en tal sentido formulada ante el Registro Civil en el plazo de cinco años desde la entrada en vigor de la presente ley. Tal declaración se hará constar en el Registro Civil, no necesita ser reiterada y no podrá ser revocada por el interesado».

Como consecuencia de la anterior supresión de adquisición automática, nos encontramos con esta Disposición transitoria para que, aquellos que la hayan perdido sin ser conscientes de ello, puedan recuperarla. Sobre el plazo de cinco años se dice que es por oportunidad y conveniencia (de hecho cuando la Ley $11 / 1990$ permitió a la mujer casada recuperar la vecindad civil perdida a causa del matrimonio, el plazo fue de un año). Y en cuanto a las dudas que podría suscitar que esta declaración no pueda ser revocada, no debería plantear ningún problema si se tiene en cuenta «el carácter indisponible de la vecindad civil como estado civil de la persona una vez que se ha hecho uso del derecho reconocido en la norma», y ello sin perjuicio de que posteriormente se pueda adquirir una nueva vecindad civil de acuerdo con las normas del $\mathrm{CC}^{88}$.

\section{DOS CUESTIONES TANGENCIALES A LA PROPOSICIÓN DE LEY}

Durante el debate parlamentario hubo dos temas que, si bien no formaban parte de ninguna de las tres modificaciones propuestas, de alguna manera incidían sobre todas ellas. Cuestiones que han sido objeto de reflexión constante por parte de la doctrina experta en el tema ${ }^{89}$ y que se refiere, por una parte, a la necesidad (o no) de la promulgación de una Ley de Derecho interregional privado y, por otra, a la necesidad (o no) de atribuir validez a las declaraciones ante Notario relativas a la vecindad civil.

Sobre la primera de ellas, ya hemos señalado que en 1946 el Congreso Nacional de Zaragoza estableció como una de sus conclusiones la necesidad de la «promulgación urgente de una ley de carácter general que

88 M. A. Egusquiza Balmaseda, en su comparecencia ante el Congreso. Diario de sesiones del Congreso de los Diputados, Comisión de Justicia, 22 de febrero de 2017, pp. 4 y 5.

89 Entre otros, J. Delgado EChEVerRía / J.A., PAStor RidRUejo, "Consideraciones generales sobre metodología y procedimiento en la elaboración de un proyecto de ley de derecho interregional", Anuario de Derecho Aragonés, XVII, 1974-1975-1976, pp. 15-22, exponiendo una posible metodología y procedimiento para la elaboración de un proyecto de ley de derecho interregional. También M. A. PARRA LUCÁN, "La vecindad civil...", op.cit., p. 55, afirmando la necesidad de una «ley general, válida para todo el territorio español, en la que, con criterios de igualdad para todas las Comunidades españolas, se regule lo concerniente a la vecindad civil» y S. Álvarez GonzÁlEZ, "Estudios de derecho interregional...", op.cit., p. 107-120, haciendo un análisis pormenorizado de cómo podría abordarse una reforma integral del régimen de Derecho interregional privado. $Y$ más recientemente, de nuevo J. DeLGado ECHEVERRÍA, "Vecindad civil y derecho...", op.cit., pp. 20-21; J. J. PÉREZ MiLLA, "Un derecho interregional entre gigantes", Cincuenta años de Derecho civil aragonés, 2017, p. 103, aunque duda que se pueda adoptar tal ley sin antes resolver muchas cuestiones del modelo territorial español; y de nuevo S. ÁlvarEZ GonZÁLEZ, "Cuestiones de Derecho interregional...", op.cit., p. 8. 
resuelva los problemas de Derecho interregional que surgen de la coexistencia de diferentes regímenes civiles en España». De hecho, tras la promulgación de la Constitución, incluso el Tribunal Constitucional esperaba que se dictase tal ley, pues en su Sentencia 72/1983, de 29 de julio, declaraba que habría que tener en cuenta lo dispuesto por el título preliminar del Código Civil (art. 9.11, en conexión con el art. 16), «en tanto no se dicte una ley postconstitucional» para solucionar estos posibles conflictos internos. Lo cierto es que, en palabras de ÁlvAREZ GonZÁLEZ, la competencia del art. 149.1.8 a CE (que no solo se refiere a conflictos internacionales, sino también internos), «no ha disfrutado de la más mínima atención por parte de quien está llamado a ejercerla: el legislador estatal» ${ }^{90}$.

En las comparecencias ante el Congreso de los Diputados se hizo hincapié en esta reivindicación, reclamando la necesidad urgente de esta ley, diciéndose que lo que hoy se aplica como Derecho interregional privado son los descartes del Derecho internacional privado que siguen en el Código, pero que no fueron pensados para eso ${ }^{91}$.

Sobre la necesidad (o no) de atribuir validez a las declaraciones ante Notario también se pronunciaron repetidamente los expertos comparecientes. Por todos, cabe destacar las palabras de OlLÉ FavARó, decano del Colegio de Notarios de Cataluña, quien propuso que cuando los ciudadanos comparezcan ante notario para firmar cualquier documento de los que se otorgan, por ejemplo un testamento o una compraventa, puedan a su vez hacer la declaración de mantenimiento de su vecindad de origen, siendo el notario el que después lo comunique al Registro Civil correspondiente.

Como ya dijimos más arriba, por ahora se sigue negando que la declaración pueda ser ante Notario, aunque ya hay voces que verían factible, en un futuro próximo, un cambio de criterio que permita realizar ante este cuerpo las declaraciones relativas a la vecindad, vistas las amplias funciones que se les están atribuyendo a estos profesionales jurídicos tras la Ley $15 / 2015$, de 2 de julio, de jurisdicción voluntaria ${ }^{92}$, postura que consideramos del todo sensata y necesaria.

\section{ENMIENDAS PRESENTADAS POR LOS GRUPOS PARLAMENTARIOS A LA PROPOSICIÓN DE LEY}

Los grupos parlamentarios presentaron diversas enmiendas a la Proposición de Ley, recogidas todas en el Boletín Oficial de las Cortes

\footnotetext{
90 S. Álvarez GonzÁlez, "Cuestiones de Derecho interregional...", op.cit., p. 8.

91 J. Delgado ECheVERría, en su comparecencia ante el Congreso. Diario de Sesiones del Congreso de los Diputados, 22 de febrero de 2017, p. 9.

92 M. A. PARRA LUCÁN, "Comentario a los artículos...", op.cit., p. 173; J. Delgado ECHEVERRÍA. "Vecindad civil y derecho...", op.cit., p. 19, quien propone dar entrada «con fuerza y claridad a la competencia del notario para la autorización de actas de declaración de adquirir o no adquirir una vecindad civil por residencia», pues «es en razón de los actos que el particular quiere realizar (ventas de inmuebles, capitulaciones, testamentos), cuando este cae en la cuenta de la trascendencia de la vecindad civil y puede recibir la información y asesoramiento necesarios para obrar en consecuencia».
} 
Generales de 4 de mayo de 2017. Las enmiendas se formulan bastante en consonancia con las posiciones que los grupos habían fijado el 15 de noviembre de 2016, día de toma en consideración de la Proposición de Ley. Grosso modo, podemos percibir básicamente dos posturas diferentes: por un lado, aquellos partidos que aceptan la Proposición de Ley tal cual es presentada por las Cortes de Aragón $\mathrm{n}^{93}$, y aquellos otros que coinciden en el mantenimiento del art. 14.5 CC sobre adquisición automática de la vecindad civil sin declaración en contrario, a la vez que modifican o mantienen otros detalles de la Proposición de Ley ${ }^{94}$. Después quedarían otros partidos que propusieron enmiendas de adición relativas a la regulación de la nacionalidad para facilitar la adquisición de la española por los saharauis ${ }^{95}$.

En primer lugar, sobre la ampliación de la facultad de opción del hijo, se formulan dos enmiendas: una de ellas mantiene la propuesta de ampliación del plazo a cinco años, pero sin que pueda optar por cualquiera de las vecindades civiles que hubiesen ostentado los progenitores. Por tanto, siguen sosteniendo lo establecido en el Código civil en cuanto a que la elección sea solo respecto a la última vecindad civil de los progenitores ${ }^{96}$. La otra enmienda prefiere mantener el texto del Código civil en cuanto al plazo de elección de un año, pero desde la mayoría de edad y no emancipación, como reza el texto actual ${ }^{97}$.

Sobre la supresión de la adquisición automática de la vecindad civil por el transcurso de diez años sin declaración en contrario, dos partidos se oponen, prefiriendo que el Código civil mantenga el vigente art. $14.5 \mathrm{CC}^{98}$. Estos dos mismos grupos también proponen enmiendas que eliminan por completo el punto II de la Exposición de motivos, en el que se explican las razones simbólicas que llevan a proponer esta reforma ${ }^{99}$.

En lo que concierne a la Disposición transitoria, un grupo propone una enmienda de supresión ${ }^{100}$, mientras que otro la mantiene eliminando solo su último inciso ${ }^{101}$, por lo que sí quieren que esa declaración para la recuperación de la vecindad perdida pueda ser revocable por el interesado, al contrario de lo que se propone por las Cortes de Aragón.

Por último, cabe mencionar una última enmienda de adición presentada por uno de los grupos, y que consideramos de vital importancia: la posibilidad de que la declaración de conservación de la vecindad civil de

\footnotetext{
${ }^{93}$ Grupos parlamentarios Socialista y UNIDOS Podemos - En Comú Podem - En Marea.

${ }^{94}$ Grupos parlamentarios Popular, Ciudadanos, y Partit Demócrata catalá.

${ }^{95}$ Grupos parlamentarios Esquerra Republicana, Vasco y Mixto. Enmiendas núms. 1, 2, 3, $4,5,7,8$ y 9 .

${ }_{96}$ Grupo parlamentario Ciudadanos, enmienda núm. 11.

97 Grupo parlamentario Popular, enmienda núm. 14.

98 Grupos parlamentarios Ciudadanos, enmienda núm. 11 y Popular, enmienda núm. 14.

${ }^{99}$ Grupos parlamentarios Ciudadanos, enmienda núm. 10, y Popular, enmienda núm. 13.

${ }^{100}$ Grupo parlamentario Ciudadanos, enmienda núm.12.

101 Grupo parlamentario Popular, enmienda núm. 15. Lo cierto es que esta enmienda resulta del todo paradójica, como señala J. DeLGADo ECHEVERRÍA. "Vecindad civil y derecho...", op.cit., p. 11, pues este mismo grupo parlamentario se opone a cambiar la regla de pérdida por los diez años de residencia.
} 
origen pueda ser manifestada ante el Notario. Así, la enmienda en cuestión dice que:

«Los ciudadanos cuando comparezcan ante notario podrán manifestar su voluntad de mantener su vecindad civil de origen. En este caso el notario o fedatario público lo recogerá en un documento público independiente y lo comunicará al Registro Civil a los efectos oportunos» ${ }^{102}$.

Al igual que buena parte de la doctrina, entendemos que sería de gran ayuda para dotar al sistema de mayor seguridad jurídica y evitar pleitos en donde las partes se enzarcen a probar una vecindad civil u otra, que se dé paso al notario como competente para la autorización de actas no solo de conservación de la vecindad civil anterior como se dice en la enmienda, sino también para dejar sentada la adquisición de la vecindad de residencia o para optar, el hijo, por cualquiera de las vecindades civiles de los padres.

En fin, las enmiendas -en especial las núm. 10 a 16- revelan que las posturas sobre las cuestiones planteadas en la Proposición de Ley son variadas, lo que más allá de razones técnicas o jurídicas, entendemos que también se explica por la concepción simbólica de la vecindad civil. Estas otras razones que podríamos llamar de «política legislativa», que ahonda en la historia e identidad de los pueblos, son las que a continuación pasamos a exponer.

\section{LA CUESTIÓN SIMBÓLICA: LA VECINDAD CIVIL COMO INSTRUMENTO DE GARANTÍA DE LA IDENTIDAD DE UN PUEBLO}

Que en un tema como la vecindad civil haya la divergencia de opiniones que acabamos de comentar no responde únicamente a razones jurídicas o técnicas. Si bien estas son importantes, no lo son menos aquellas otras que atienden a razones políticas, históricas o identitarias. El Derecho de familia y sucesiones, en donde la vecindad civil tiene un papel fundamental, es en donde juega también con mayor fuerza el papel identitario, habiéndose afirmado que el derecho aplicable en estos ámbitos debe ser el del lugar en el que las partes tengan un vínculo particularmente fuerte, lo que se denomina «arraigo» ${ }^{103}$. En España, es la vecindad civil la que encauza este arraigo. Si en el aspecto técnico-jurídico la vecindad civil sirve para determinar el Derecho civil aplicable, desde el punto de vista simbólico concede una identidad, ya sea foral o común/nacional, dentro del territorio español ${ }^{104}$.

102 Grupo parlamentario Mixto, enmienda núm. 16.

103 Sobre la idea del arraigo, en la STC $156 / 1993$ ya comentada se dice que «la facilidad para adquirir o perder la mera residencia entraña, por sí misma, la posibilidad de que la legislación balear resulte aplicable sin que el interesado tenga su centro de vida o arraigo suficiente en el territorio de dicha Comunidad. Lo que indudablemente afecta de modo negativo a la estabilidad y permanencia que tradicionalmente se ha considerado que son inherentes a la ley personal, dadas las materias que ésta rige según el art. 9.1 del Código Civil ("la capacidad y el estado civil, los derechos y deberes de familia y la sucesión por causa de muerte")» (FJ $\left.3^{\circ}\right)$.

${ }^{104}$ A. FonT I SegurA, Actualización y desarrollo... op.cit., p. 237-239 lo ve así, si bien dice que para que aporten identidad los derechos civiles, deben estar en confrontación con otros ordenamientos. 
Conocedoras del peso de estos motivos las Cortes de Aragón lo dejan claro en el segundo punto de la Exposición de Motivos de la Proposición de Ley: «En Aragón hablar de raíces es hablar de nuestro derecho propio, del derecho foral que históricamente ha presidido nuestra convivencia. Se trata de un estatuto personal que sigue al aragonés desde su nacimiento, regulando la economía de su matrimonio, la familia, la viudedad y los derechos hereditarios cualquiera que sea su domicilio y lugar en el que se encuentre, conforme al Código de Derecho foral aprobado por las Cortes de Aragón en 2011». También los tres representantes de las Cortes de Aragón que defendieron la Propuesta de Ley ante el Congreso de los Diputados hicieron alusión a esta función «cuasi-metajurídica» ${ }^{105}$, en palabras de FONT I SEGURA, que se atribuye a la vecindad civil. Así, por ejemplo, VALLÉs CASES dice que defienden la Proposición de ley con argumentos políticos, históricos y jurídicos, siendo su finalidad la de adecuar la regulación de la vecindad civil a «nuestra realidad y conciencia social» ${ }^{106}$.

Asimismo, varios de los expertos comparecientes se apoyaron en la cuestión simbólica de la vecindad civil para defender la aprobación de la Proposición de Ley. Al referirse a la supresión de la adquisición automática de la vecindad civil por residencia de diez años continuada en otro territorio - la modificación que más representa este sentir «identitario» de la vecindad civil - dijeron, por ejemplo, que «cuando un catalán, un balear, un gallego, un vizcaíno, un navarro o un aragonés marcha a vivir a otro territorio, así como que no pierde inmediatamente su lengua, su concepción, su tradición o el amor a su tierra, así tampoco debería perder tan simplemente la conexión con el ordenamiento territorial (...)» ${ }^{107}$. Esto conecta con la idea de que hay territorios de inmigración y de emigración, de que hay regiones que captan población a la vez que otras la pierden: y

\footnotetext{
105 A. Font i Segura, Actualización y desarrollo... op.cit., p. 239.

${ }^{106}$ Así se recoge en el Diario de sesiones del Congreso de los Diputados, del día en el que se tomó en consideración la Proposición de Ley comentada, 15 de noviembre de 2016, pp. 5-17. Los otros dos diputados aragoneses que comparecieron ese día no dejaron de mencionar los motivos históricos que les llevaban a defender esta Propuesta. A. Herrero HERRERO se refirió a «esta tierra de gente noble, el viejo Reino de Aragón, pueblo milenario de hondas raíces, nacionalidad histórica incuestionable», y G. J. BRIZ SÁNCHEZ a la importancia del derecho aragonés como «símbolo de identidad de los aragoneses para Aragón», a la vez que hacía un barrido por la historia de Aragón desde los tiempos de Felipe $\mathrm{V}$ para mencionar que, si bien perdieron otras cosas, nunca perdieron el derecho civil, nunca se regularon «por un derecho diferente al nuestro». A. HeRRERO HeRRERO y G. J. BRIZ SÁNCHEZ en sus comparecencias en la toma en consideración de la Proposición de Ley. Diario de sesiones del Congreso de los Diputados, 15 de noviembre de 2016.

107 G. OROzCo PARDo, en su comparecencia ante el Congreso. Diario de sesiones del Congreso de los Diputados, Comisión de Justicia, 4 de abril de 2017, p. 4. No obstante, estas declaraciones contrastan con lo dicho por algún diputado en la toma en consideración de la Proposición de Ley. Así, en palabras uno de los diputados del grupo Podemos, se recoge en el Diario de sesiones del Congreso, 15 de noviembre de 2016, p. 13 , que les «preocupa que vinculen algo tan subjetivo, tan íntimo y tan personal como la identidad territorial a la vecindad civil. [Creen] que no hay un ordenamiento que pueda atribuir a la esfera íntima de una persona el sentimiento de pertenencia a un territorio o a una comunidad».
} 
ello implica, con la actual regulación de la vecindad civil, que a la larga se pueda ir perdiendo también el derecho de la región que sufre esas pérdidas de población.

En definitiva, como bien dice Delgado ECHEVERRÍA, está claro que «las "vecindades forales", contrapuestas al "Derecho común", son testimonio de la diversidad y designan a aquellos que tienen un Derecho diferente, suyo propio» y que la vecindad civil, como instrumento que sirve para determinar la aplicación de los diferentes derechos que conviven en nuestro país, tiene por ello un gran valor simbólico, de «apelación a los afectos, a los sentimientos de pertenencia y a las identidades colectivas ${ }^{108}$.

\section{CONCLUSIONES}

Más de dos años después de la toma en consideración de la Proposición de Ley presentada por las Cortes de Aragón por la que se modifica el Código Civil en relación con el estatuto personal y vecindad civil, no es insensato decir que hoy «duerme el sueño de los justos», y aunque no somos quien de aventurarnos a afirmar que no se aprobará, todo parece apuntar a que así será. Por otra parte, que se quiera modificar el régimen de la vecindad civil no es algo que haya surgido espontáneamente hace dos-tres años de las Cortes de Aragón, sino que como mínimo parece remontarse al Congreso Nacional de Derecho civil celebrado en Zaragoza entre el 3 y el 9 de octubre de 1946, en el que se contemplaron los problemas planteados por «unos regímenes forales que tienen plena vigencia y arraigo innegables y cuentan con el afecto de los naturales del territorio en que rigen». Por ello, tampoco nos extrañaría que dentro de un tiempo se retomase el debate, bien sea «reciclando» esta Proposición de Ley, bien sea de otra manera, por lo que toda la discusión surgida a raíz de ella no habrá sido en vano. O quizá se vuelva sobre el tema de la vecindad civil a raíz de algunas cuestiones suscitadas con la Ley 5/2015 de Derecho Civil Vasco, y que como vimos plantean serias dudas de constitucionalidad.

La Proposición de Ley pretende modificar, esencialmente, tres aspectos de la vecindad civil. En primer lugar, que el hijo tenga mayor libertad de decisión a la hora de optar por la vecindad civil una vez que cumpla catorce años (supuesto del art. 14.3 párrafo cuarto CC), lo que se refleja en la ampliación del plazo de un año del que actualmente dispone tras su emancipación, a cinco años, y además podrá optar no solo por la última vecindad de cualquiera de los progenitores, sino por cualquiera que hubiesen tenido. Los expertos que fueron llamados a comparecer en el Congreso de los Diputados expresaron, en su gran mayoría, su acuerdo con esta modificación. Hicieron una comparativa con las reformas que han ido ampliando la posibilidad que se concede a los hijos de optar por la nacionalidad española, y aunque el plazo de opción es diferente, se valora como indudable mejora desde los parámetros del ejercicio subjetivo por parte del hijo mayor de catorce años. Sobre la posibilidad de que puedan

108 J. Delgado EcheVerRía, "Vecindad civil y derecho...", op.cit. p. 9. 
optar por cualquiera de las vecindades civiles que hayan tenido los progenitores, algunos diputados se mostraron escépticos, criticando la fórmula por ser demasiado abierta (sobre todo cuando los progenitores hayan tenido varias vecindades), pudiendo elegirse una con la que la persona no tenga ninguna vinculación, lo que podría generar cierta inseguridad. En nuestra opinión, y partiendo de la consagrada igualdad entre los diferentes ordenamientos jurídicos españoles, nada obsta a que las opciones sean mayores, siempre y cuando se justifique debidamente. En este caso, que los progenitores hayan ostentado la vecindad elegida nos parece una justificación suficiente. Otra cosa será, no obstante, probar que tuvieron dicha vecindad, pues como ya se expuso son notables los problemas de prueba con la actual regulación.

En segundo lugar, la Proposición de Ley plantea la supresión de la adquisición de la vecindad civil por residencia continuada de diez años, supuesto previsto actualmente en el art. 14.5 CC. La Exposición de Motivos de la Proposición justifica dicha supresión en que parece excesivo que se pierda sin declaración ninguna del interesado, y sin hacer ninguna averiguación sobre si se quiere o no cambiar su estatuto personal. Es en este extremo en donde más divergencias hubo tanto en las opiniones de los llamados a comparecer ante el Congreso, como en las enmiendas posteriormente presentadas por los Grupos parlamentarios. Sintéticamente, las justificaciones que se dieron en apoyo a la reforma y en la línea con la idea de prevalencia del origen apelaron a la autonomía de la voluntad y la seguridad jurídica, diciéndose sobre la primera que debe primar la declaración libre y espontánea de querer conservar o no la vecindad civil, frente a la adquisición automática de la vecindad del lugar en el que se reside diez años. Si bien algunos comparecientes y doctrina han considerado que en este último caso opera una presunción de voluntad o voluntad tácita, en nuestra opinión no existe tal voluntad, sino una mera adquisición automática ex lege. Los defensores de la Proposición de Ley exponen, en este sentido, que dará mucha más seguridad jurídica que solo por voluntad expresa se pueda cambiar de vecindad civil, lo que permitiría acabar con problemas de pérdidas de vecindad civil indeseadas. No obstante, no fueron de esta opinión todos los expertos ni diputados, quienes dieron argumentos en contra de dicha reforma, diciendo que con ella se generarían casos de personas con vecindades civiles distintas al territorio de residencia y sin ninguna vinculación con el territorio cuya vecindad ostentasen, más allá del vínculo que, de ser el caso, pudiesen haber tenido los progenitores. En este sentido, es curioso que se acuda de nuevo al principio de seguridad jurídica para justificar esta postura, entendiendo sus defensores que daría más inseguridad el hecho de disociar totalmente la vecindad civil y la residencia habitual -salvo en los casos en que el interesado opte expresamente, al cabo de dos años de residencia, por la vecindad del lugar- que adquirir automáticamente una vecindad ex lege, sin voluntad expresa. Por el contrario, en nuestra opinión, nada puede proporcionar más seguridad jurídica que una declaración libre y expresa de voluntad, ya sea de querer conservar la 
vecindad civil de origen, ya sea de querer obtener la del lugar en el que se reside.

La supresión de la adquisición automática de la vecindad civil fue el extremo de la Proposición de Ley en donde se hizo más patente la cuestión simbólica de la vecindad civil. Las diferentes opiniones doctrinales, las divergencias en las comparecencias de los diputados, y las explicaciones que podemos dar a la existencia de enmiendas que eliminan este extremo de la Proposición de Ley, muestra que existen no solo razones técnicas, sino también políticas, históricas o identitarias, que afectan a la institución de la vecindad civil. Así, podrían no percibirse de la misma manera las modificaciones propuestas según qué vecindad civil tenga el experto compareciente o diputado, o según sea mayor o menor su arraigo en determinados lugares. En general, podría decirse que aquellos provenientes de territorios a los que se emigra, estarían a favor del mantenimiento del régimen vigente, pues permite que los que allí residen adquieran, aún sin percatarse de ello, la vecindad civil de ese territorio. En cambio, aquellos otros originarios de regiones que históricamente han ido perdiendo población, abogarían por el cambio de régimen que permita conservar la vecindad civil de origen, y con ello el derecho de dicho territorio. No obstante, el posicionamiento a un lado o a otro de la balanza no creemos que resulte tan relevante si entendemos que lo verdaderamente importante es, como dijimos en el párrafo anterior, que se atienda a la declaración expresa de voluntad, y que permitiría que tanto unos como otros conserven su vecindad (sin pérdidas involuntarias por el transcurso del tiempo) u opten voluntariamente a los dos años por la vecindad del territorio en el que residan.

Por último, la propuesta contiene una disposición transitoria que permitiría recuperar la vecindad civil perdida mediante una declaración en el Registro Civil, cuestión que va en línea con la anterior modificación y que por tanto creemos acertada, pues se estaría poniendo remedio a aquellas situaciones de pérdida de vecindad civil involuntaria. Para ello se dispondría de un plazo de cinco años, sin posibilidad de revocar esta declaración. Sobre este extremo, el consenso entre expertos y parlamentarios fue mayor, si bien es cierto que un grupo presenta una enmienda de supresión de dicha disposición.

Entre el resto de enmiendas presentadas por los grupos parlamentarios a la Proposición de Ley, cabe mencionar aquella de adición en la que se faculta al Notario para recoger las declaraciones de voluntad de querer conservar la vecindad civil de origen, siendo el Notario el que después lo comunique al Registro Civil. Lo cierto es que atribuir validez a las declaraciones ante Notario sobre vecindad civil, ya sea para conservar la de origen, ya sea para optar por alguna de las vecindades civiles de los progenitores, nos parece algo de lo más sensato, pues es ante este profesional ante el que se suelen plantear las relaciones jurídicas en las que la vecindad civil juega un papel esencial. Además, ello iría en consonancia con las amplias funciones que se les están atribuyendo a los Notarios tras la Ley 15/2015, de 2 de julio, de jurisdicción voluntaria, y 
facilitaría lo ya concluido en el Congreso de Zaragoza de 1946: que la vecindad civil debería ser fácil y sencillamente conocida.

Quizá todas estas reformas podrían proyectarse en el marco de la tan solicitada Ley de Derecho Interregional, que ni siquiera ha tenido la suerte de ser planteada para su debate parlamentario como sí le ha sucedido a esta Proposición de Ley. En definitiva, lo cierto es que la dejadez del legislador estatal en este tema contrasta con el compromiso e interés que siempre ha mostrado la Comunidad Autónoma de Aragón por actualizar el régimen de la vecindad civil, incluso desde antes del mencionado Congreso de Zaragoza de 1946 y hasta la presentación de la Proposición de Ley comentada, tratando de solventar la desgana estatal por lo menos en aquellos puntos de la regulación que consideran más relevantes o de urgente actualización. Que no se haya aprobado finalmente la Proposición de Ley no puede empañar el mérito que tiene el haber dedicado un notable esfuerzo a una cuestión que no atañe solo a la Comunidad Autónoma de Aragón, sino a todos los españoles, tengamos la vecindad civil que tengamos y cualquiera que sea nuestra percepción política o identitaria.

\section{BIBLIOGRAFÍA}

M. Alonso MARTínez, El Código civil en sus relaciones con las legislaciones forales, Madrid, Est. Tipográfico de P. Núñez, 1884.

S. Álvarez GonzÁlez, Estudios de Derecho interregional, De Conflictu Legum, Estudios de Derecho internacional privado, núm. 9, Santiago de Compostela, 2007.

S. Álvarez GonzÁlez, "Legítimas y Derecho interregional", Tratado de legtítimas, Torres García, T. (Coord.), Atelier, 2012, pp. 153-202.

S. Álvarez González, "Domicilio, vecindad civil y nacionalidad", Tratado de Derecho de la persona física, Tomo II, M.C. Gete-Alonso y CALERA, (Dir.), Civitas-Thomson Reuters, Navarra, 2013, pp. 340-361.

S. Álvarez GonzÁlez, "La «eficacia territorial» del Derecho civil autonómico como (no) criterio de aplicación en situaciones internacionales", Revista de Derecho Civil, vol. IV, núm. 3, 2017, pp. 35-62.

S. Álvarez GonzÁlez, "Cuestiones de Derecho interregional en la aplicación de los nuevos reglamentos comunitarios", versión escrita, pendiente de publicación, de la participación en la mesa redonda bajo el mismo título que tuvo lugar el 20 de marzo de 2018, en la sede del Colegio de Notarios de Cataluña, a la que he tenido acceso por gentileza del autor.

R. Bercovitz Rodríguez-Cano, "Artículos 14 y 15", Comentarios a las Reformas del Código Civil. El nuevo Título Preliminar del Código y la Ley de 2 de mayo de 1975, Tecnos, Madrid, 1977, pp. 703-729.

R. Bercovitz Rodríguez-Cano, "Artículos 13, 14 y 15", Comentarios al Código Civil, R. Bercovitz Rodríguez-Cano (Dir.), Thomson-Aranzadi, Cizur Menor (Navarra), 2006, pp. 105-115.

R. Bercovitz Rodríguez-Cano, "Comentario a la Sentencia de 14 de septiembre de 2009: Vecindad civil; fraude de ley", Cuadernos Civitas de jurisprudencia civil, núm. 83, 2010, pp. 1093-1122. 
J. Bermejo Vera / J. Delgado Echeverría, "Artículo 9", Comentarios al Estatuto de Autonomía de la Comunidad Autónoma de Aragón J. BERMEJO VerA (Dir.), Instituto de Estudios de Administración local, Madrid, 1985, pp. 81-90.

G. J. BRIZ SÁNCHEZ, Comparecencia en la toma en consideración de la Proposición de Ley. Diario de sesiones del Congreso de los Diputados, 15 de noviembre de 2016.

A. CalATAYUd, "La unidad del derecho interregional", Revista del Colegio Notarial de Madrid, núm. 37, mayo-junio 2011, pp. 132-135.

O. Casanovas y La Rosa, "Art. 16.1. CC", El nuevo Título Preliminar del Código y la Ley de 2 de mayo de 1975, Tecnos, Madrid, 1977, pp. 730-749.

P. Cremades García, "Artículos 92 y 93", Comentarios a la Ley de Registro Civil, J.A. Cobacho Gómez / A. LeCiñena IbarRa (Dirs.), Thomson Reuters-Aranzadi, Navarra, 2012, pp. 1257-1271.

F. De Castro y Bravo, Derecho civil de España, Civitas, Madrid, 1952.

J. Delgado Echeverría / J.A., Pastor Ridruejo, "Consideraciones generales sobre metodología y procedimiento en la elaboración de un proyecto de ley de derecho interregional", Anuario de Derecho Aragonés, XVII, 1974-1975-1976, pp. 15-22.

J. Delgado Echeverría, "Artículo 14", Comentarios a las reformas del Código civil. Desde la Ley 21/1987, de 11 de noviembre, a la Ley 30/1991, de 20 de diciembre, R. Bercovitz Rodríguez-CANo (Coord.), Tecnos, 1993, pp. 305-324.

J. Delgado Echeverría, "Comentarios a los artículos 14 y 15 CC", Comentarios al Código civil, I, Título preliminar, J. RAMS AlbeSA, (Coord.), Bosch, Barcelona, 2000, pp. 287-419.

J. Delgado EChEVERRÍA, comparecencia ante el Congreso. Diario de sesiones del Congreso de los Diputados, Comisión de Justicia, 22 de febrero de 2017.

J. Delgado EcheVerRía, "Vecindad civil y derecho interregional privado: una reforma necesaria", Lección inaugural de la apertura de curso de la Academia Vasca de Derecho, pronunciada el 25 de octubre de 2017 en la sede del Colegio Notarial del País Vasco.

R. DuRÁn Rivacoba, "Comentario a la sentencia del Tribunal Supremo de 16 de diciembre de 2015 (5808/2015). Cómputo del plazo en materia de adquisición de la vecindad civil", Comentarios a las sentencias de unificación de jurisprudencia, Vol. 7, Dykinson, 2015, pp. 731-745.

R. DURÁn RivacoBA, comparecencia ante el Congreso. Diario de sesiones del Congreso de los Diputados, Comisión de Justicia, 22 de febrero de 2017.

M. A. Egusquiza Balmaseda, comparecencia ante el Congreso. Diario de Sesiones del Congreso de los Diputados, Comisión de Justicia, 22 de febrero de 2017.

J. C. Fernández Rozas / P. Rodríguez Mateos / S. Álvarez González, Derecho español de la nacionalidad, Tecnos, Madrid, 1987. 
A. Font y Segura, Actualización y desarrollo del sistema de Derecho interregional, De Conflictu Legum, Estudios de Derecho internacional privado, Universidade de Santiago de Compostela, 2007.

O. Galeano Gracia, Comparecencia en la toma en consideración de la Proposición de Ley. Diario de sesiones del Congreso de los Diputados, 15 de noviembre de 2016.

M.P. GARCÍA RuBio, "Presente y futuro del Derecho civil español en clave de competencias normativas", Revista de Derecho Civil, vol. IV, núm. 3 (julio-septiembre, 2017), Estudios, pp. 1-33.

M. P. García Rubio / F. Méndez García, Douscentos anos do Code civil des Francais na USC (1804-2004), Universidad de Santiago de Compostela, 2005.

M. E. GinebRa Molins, comparecencia ante el Congreso. Diario de sesiones del Congreso de los Diputados, Comisión de Justicia, 9 de marzo de 2017.

J. A. Herrero Herrero, Comparecencia en la toma en consideración de la Proposición de Ley. Diario de sesiones del Congreso de los Diputados, 15 de noviembre de 2016.

J. L. IRIARTE ÁnGEL, "Ámbito material y personal y normas conflictuales", El Derecho civil vasco del siglo XXI. De la ley de 2015 a sus desarrollos futuros, Colección informes y documentos serie maior del Parlamento Vasco, Bilbao, 2016, pp. 136-161.

J. L. LACRUz Berdejo, "El Congreso Nacional de Derecho Civil de 1946", Anuario de Derecho Civil, núm. 1, 1948, pp. 145-155.

C. LASARTE Álvarez, comparecencia ante el Congreso. Diario de sesiones del Congreso de los Diputados, Comisión de Justicia, 9 de marzo de 2017.

J. J. Lavilla Rubira, "Las proposiciones de ley remitidas por las Comunidades Autónomas al Congreso de los Diputados", Revista Española de Derecho Constitucional, Año 10, núm. 28, enero-abril 1990, pp. 9-73.

M. LiRia Lafarga, "La Regionalidad o Vecindad civil", Jornadas de Derecho Foral, Jaca 27-31 agosto, 1972.

A. López AzCona, "La política legislativa de la Comunidad autónoma de Aragón en materia de Derecho civil propio: de la Compilación de 1967 al Código del Derecho foral de Aragón de 2011 e iniciativas legislativas ulteriores", Iura Vasconiae, 13/2016, pp. 341-402.

M. MARTínez MARTíneZ, comparecencia ante el Congreso. Diario de Sesiones del Congreso de los Diputados, BOE de 22 de febrero de 2017.

L. L. Montes BeL, comparecencia ante el Congreso. Diario de Sesiones del Congreso de los Diputados, Comisión de Justicia, 22 de febrero de 2017.

G. Orozco PARDo, comparecencia ante el Congreso. Diario de sesiones del Congreso de los Diputados, Comisión de Justicia, 4 de abril de 2017.

M. A. PARRA LuCÁn, "La vecindad civil: en torno a un proyecto de reforma", Revista Jurídica de Navarra, núm. 5, Navarra, 1988, pp. 53-80.

M. A. PARRA LuCÁn, "Comentarios a los artículos 14 y 15 CC", Código civil comentado, R. Valpuesta Fernández, / P. De Pablo Contreras, / A. 
Cañizares Laso, / J. Orduña Moreno (Dirs.), Civitas - Thomson Reuters, Cizur Menor (Navarra), 2016, pp. 168-183.

J.J. PÉrez Milla, "Un derecho interregional entre gigantes", Cincuenta años de Derecho civil aragonés, 2017, pp. 77-104.

R. PRATdesabA I RicARD, comparecencia ante el Congreso. Diario de sesiones del Congreso de los Diputados, Comisión de Justicia, 9 de marzo de 2017.

L. Puig Ferriol, en el prólogo al libro de I. Ribas Algueró, La vecindad civil: problemática en torno a su régimen jurídico y a su prueba, Bosch, Barcelona, 1984.

I. Ribas Algueró, la Vecindad civil: problemática en torno a su régimen jurídico y a su prueba, Bosch, Barcelona, 1984.

M. E. Zabalo Escudero, "Autonomía de la voluntad, vecindad civil y conflictos de leyes internos", Autonomía de la voluntad en el derecho privado: Estudios en conmemoración del 150 aniversario de la Ley del Notariado, L. Prats Albentosa (Coord.) Vol. 5, 2012, pp. 389-511. 